\title{
Tetrabenazine Facilitates Exocytosis by Enhancing Calcium-Induced Calcium Release through Ryanodine Receptors
}

\author{
(1) Ricardo de Pascual, Nuria Álvarez-Ortego, (1)Cristóbal de los Ríos, \\ Gema Jacob-Mazariego, and Antonio G. García \\ Instituto Teófilo Hernando, Madrid, Spain (R.d.P., N.Á.-O., C.d.I.R., G.J.-M., A.G.G.); and Departamento de Farmacología y \\ Terapéutica (R.d.P., N.Á.-O., G.J.-M., A.G.G.) and Instituto de Investigación Sanitaria, Hospital Universitario de la Princesa \\ (C.d.I.R., A.G.G.), Facultad de Medicina, Universidad Autónoma de Madrid, Madrid, Spain
}

Received March 11, 2019; accepted June 4, 2019

\begin{abstract}
Vesicular monoamine transporter-2 is expressed in the presynaptic secretory vesicles membrane in the brain. Its blockade by tetrabenazine (TBZ) causes depletion of dopamine at striatal basal ganglia; this is the mechanism underlying its long-standing use in the treatment of Huntington's disease. In the frame of a project aimed at investigating the kinetics of exocytosis from vesicles with partial emptying of their neurotransmitter, we unexpectedly found that TBZ facilitates exocytosis; thus, we decided to characterize such effect. We used bovine chromaffin cells (BCCs) challenged with repeated pulses of high $\mathrm{K}^{+}$. Upon repeated $\mathrm{K}^{+}$pulsing, the exocytotic catecholamine release responses were gradually decaying. However, when cells were exposed to TBZ, responses were mildly augmented and decay rate delayed. Facilitation of exocytosis was not due to $\mathrm{Ca}^{2+}$ entry blockade through voltage-activated calcium channels (VACCs) because, in fact, TBZ mildly blocked the whole-cell $\mathrm{Ca}^{2+}$ current. However, TBZ mimicked the facilitatory effects of exocytosis elicited by BayK8644 (L-subtype VACC agonist), an effect blocked by nifedipine (VACC antagonist). On the basis that TBZ augmented the secretory responses to caffeine (but not those of histamine), we monitored its effects on cytosolic $\mathrm{Ca}^{2+}$
\end{abstract}

elevations $\left(\left[\mathrm{Ca}^{2+}\right]_{\mathrm{c}}\right)$ triggered by caffeine or histamine. While the responses to caffeine were augmented twice by TBZ, those of histamine were unaffected; the same happened in rat cortical neurons. Hence, we hypothesize that TBZ facilitates exocytosis by increasing $\mathrm{Ca}^{2+}$ release through the endoplasmic reticulum ryanodine receptor channel (RyR). Confirming this hypothesis are docking results, showing an interaction of TBZ with RyRs. This is consonant with the existence of a healthy $\mathrm{Ca}^{2+}$-induced$\mathrm{Ca}^{2+}$-release mechanism in BCCs.

\section{SIGNIFICANCE STATEMENT}

A novel mechanism of action for tetrabenazine (TBZ), a drug used in the therapy of Huntington's disease (HD), is described here. Such mechanism consists of facilitation by combining TBZ with the ryanodine receptor of the endoplasmic reticulum, thereby increasing $\mathrm{Ca}^{2+}$-induced $\mathrm{Ca}^{2+}$ release. This novel mechanism should be taken into account when considering the efficacy and/or safety of TBZ in the treatment of chorea associated with HD and other disorders. Additionally, it could be of interest in the development of novel medicines to treat these pathological conditions.

\section{Introduction}

The vesicular monoamine transporter (VMAT) uses a vesicle acidic $\mathrm{pH}$ gradient as a driving force to transport dopamine (DA), noradrenaline (NA), or serotonin [5-hydroxytryptamine (5-HT)] from the cytosol into the synaptic vesicle lumen (Henry et al., 1994). Two transporter subtypes have been characterized so far: VMAT1 localizes to the peripheral nervous system and central nervous system (CNS), while VMAT2 is expressed in vesicles at presynaptic nerve

This work was supported by the Ministerio de Ciencia, Innovación y Universidades [Grant SAF 2016-78892-R], Spain; European Union Horizon 2020 Research and Innovation Programme under the Marie Skoldowska-Curie Grant Agreement [Grant 766124]; and Cátedra Nutrinfant Universidad Autónoma de Madrid/Alter.

https://doi.org/10.1124/jpet.119.256560. terminals of the CNS (Erickson et al., 1995; Benarroch, 2013). The classic blockers of VMAT are reserpine and tetrabenazine (TBZ). Reserpine unselectively and irreversibly blocks both VMAT1 and VMAT2, thereby depleting vesicle monoamine contents centrally and peripherally; as a consequence, reserpine, which was classically used as an antihypertensive medicine, causes depression, orthostatic hypotension, bradycardia, and diarrhea due to parasympathetic dominance. In contrast, by selectively blocking VMAT2 in the CNS, TBZ causes depletion of dopamine, NA, and 5-HT only centrally, thus precluding the peripheral side effects of reserpine. Since long, both drugs have been used in the treatment of chorea associated with Huntington's disease (HD) and other hyperkinetic disorders; however, because of its higher safety, only TBZ is currently being used in the clinic (Jankovic, 2016).

ABBREVIATIONS: 2-APB, 2-aminoethyldiphenyl borinate; BayK, BayK8644; BCC, bovine chromaffin cell; CC, chromaffin cell; CICR, Ca ${ }^{2+}$ induced $\mathrm{Ca}^{2+}$ release; CNS, central nervous system; CPA, cyclopiazonic acid; DHP, dihydropyridine; ER, endoplasmic reticulum; HD, Huntington's disease; 5-HT, 5-hydroxytryptamine; $\mathrm{IP}_{3} \mathrm{R}$, inositol 1,4,5-trisphosphate receptor; NA, noradrenaline; RyR, ryanodine receptor; SERCA, sarcoendoplasmic reticulum calcio ATPase; TBZ, tetrabenazine; VACC, voltage-activated calcium channel; VMAT, vesicular monoamine transporter. 
For decades, reserpine has been widely used to deplete centrally the neurotransmitters NA and 5-HT to induce an animal model of depression and to develop antidepressive drugs (Hendley and Welch, 1975; Antkiewicz-Michaluk et al., 2014; Blasco-Serra et al., 2015; Ikram and Haleem, 2017). It has also extensively been used as a pharmacological tool to cause the depletion of NA from peripheral sympathetic nerve terminals (Mandela et al., 2010) and to elicit the depletion of NA and adrenaline from adrenal medullary chromaffin cells (CCs) (Dixon et al., 1975). Reserpine binds irreversibly to VMAT1 and VMAT2, thus blocking the sequestration of cytosolic monoamines, to gradually decrease their vesicle concentrations. Reserpine has also been used as an experimental tool to study how the vesicle content of catecholamines impinges in the final steps of exocytosis in adrenal CCs (Mundorf et al., 2000; Mark Wightman et al., 2018).

Following this research topic, we planned a study to investigate if TBZ, as reserpine does, could also depress the catecholamine release responses in bovine chromaffin cells (BCCs) repeatedly challenged with pulses of high potassium $\left(\mathrm{K}^{+}\right)$. Although scarcely, VMAT2 is also expressed in CCs (Weihe et al., 1994), and thus, we were curious to know the effects of TBZ on those secretory responses. We were surprised to find that, rather than causing a gradual decrease of secretory responses as a consequence of VMAT2 blockade, TBZ caused a remarkable facilitation of catecholamine release. We report here the mechanism of action of such facilitation of exocytosis that seemed to be unrelated to VMAT2 blockade; rather, such effect is apparently linked to the ability of TBZ to release $\mathrm{Ca}^{2+}$ through the ryanodine receptor channel (RyR) of the endoplasmic reticulum (ER) of BCCs and rat embryo cortical neurons.

\section{Materials and Methods}

Preparation of Chromaffin Cell Cultures. All experiments were carried out in accordance with the guidelines established by the National Council on Animal Care and were approved by the local Animal Care Committee of the Universidad Autónoma de Madrid. BCCs were isolated from calf adrenal medullary tissues obtained from a local slaughterhouse, isolated according to Moro et al. (1990) with some modifications (De Pascual et al., 2016), and plated at a density of $5 \times 10^{6}$ cells per $5 \mathrm{ml}$ of Dulbecco's modified Eagle's medium on 6 -cmdiameter Petri dishes (to study secretion) and on 12-mm-diameter glass coverslips at a density of $5 \times 10^{4}$ cells/coverslip to study calcium currents $\left(\mathrm{I}_{\mathrm{Ca}}\right)$ through voltage-activated calcium channels (VACCs). Cells were kept for $1-4$ days at $37^{\circ} \mathrm{C}$ in a water-saturated incubator in a $5 \% \mathrm{CO}_{2} / 95 \%$ air atmosphere.

On-Line Monitoring of Catecholamine Release from Perifused Cell Populations. Cells were scraped off carefully from the bottom of the Petri dish $\left(5 \times 10^{6}\right.$ cells per dish $)$ with a rubber policeman and centrifuged at $100 \mathrm{~g}$ for 10 minutes. The cell pellet was resuspended in $200 \mu \mathrm{l}$ of Krebs-HEPES solution (composition: $144 \mathrm{mM} \mathrm{NaCl}, 5.9 \mathrm{mM} \mathrm{KCl}, 1.2 \mathrm{mM} \mathrm{MgCl} 2,11 \mathrm{mM}$ glucose, $10 \mathrm{mM}$ HEPES, $2 \mathrm{mM} \mathrm{CaCl}_{2}$ (pH 7.4) with $\mathrm{NaOH}$ ). Cells were introduced in a 100- $\mu$ l microchamber, which was previously filled with a filter for cell retention, and perifused at a rate of $2 \mathrm{ml} / \mathrm{min}$. Both cells and perfusate were held at a temperature of $37^{\circ} \mathrm{C}$. The liquid flowing from the superfusion chamber reached an electrochemical detector (model CH-9100; Metrohm AG, Herisau, Switzerland) placed just at the outlet of the microchamber, which monitors online the amount of catecholamines secreted under the amperometric mode (Green and Perlman, 1981; Borges et al., 1986; De Pascual et al., 2016). The catecholamines present in the perfusate were oxidized at $+0.65 \mathrm{~V}$, and the oxidation current was recorded with a frequency of $2 \mathrm{~Hz}$ to monitor the amount of total catecholamine secreted (Borges et al., 1986). Computer-controlled solenoid valves were used to rapidly exchange the solutions. Cells were intermittently stimulated at 1-minute intervals with a solution enriched in $\mathrm{K}^{+}(35 \mathrm{mM} \mathrm{KCl}$ with concomitant reduction of $\mathrm{NaCl}$ ). Representative records of secretory responses shown in this report were accomplished by importing the data obtained in American Standard Code for Information Interchange format to the Origin 8.0 (Microcal) program.

Electrophysiological Recording of Ion Currents. Inward currents through voltage-activated $\mathrm{Na}^{+}$channels $\left(\mathrm{I}_{\mathrm{Na}}\right)$ and VACCs $\left(\mathrm{I}_{\mathrm{Ca}}\right)$ were recorded using the whole-cell configuration of the patchclamp technique (Hamill et al., 1981). Cells were perifused at $23 \pm 2^{\circ} \mathrm{C}$ with a Tyrode solution containing $137 \mathrm{mM} \mathrm{NaCl}, 1 \mathrm{mM} \mathrm{MgCl} 2,2 \mathrm{mM}$ $\mathrm{CaCl}_{2}, 10 \mathrm{mM}$ HEPES/NaOH (pH 7.4). Once the patch membrane was ruptured and the whole-cell configuration of the patch-clamp technique had been established, the cell was locally, rapidly, and constantly perifused with an extracellular solution of similar composition to the chamber solution, but containing $2 \mathrm{mM} \mathrm{Ca}^{2+}$ to monitor $\mathrm{I}_{\mathrm{Ca}}$. To measure $\mathrm{I}_{\mathrm{Ca}}$, cells were internally dialyzed with an intracellular solution containing $100 \mathrm{mM}$ Cs-glutamate, $14 \mathrm{mM}$ EGTA, $20 \mathrm{mM}$ TEA-Cl, $10 \mathrm{mM} \mathrm{NaCl}, 5 \mathrm{mM} \mathrm{Mg-ATP}, 0.3 \mathrm{mM}$ Na-GTP, and $20 \mathrm{mM}$ HEPES/CsOH ( $\mathrm{pH}$ 7.3). We used the protocol for $\mathrm{I}_{\mathrm{Ca}}$ data acquisition; cells were voltage clamped at $-80 \mathrm{mV}$, and step depolarizations with $50-\mathrm{ms}$ depolarizing pulses were applied at 30 -second intervals to minimize current rundown (Fenwick et al., 1982).

Data were acquired with a sample frequency of $20 \mathrm{kHz}$ using the PULSE 8.74 software (Heka Elektronic, Lambrecht, Germany). Linear leak and capacitive components were subtracted by using a P/4 protocol, and series resistance was compensated by $80 \%$. The data analysis was performed with Igor Pro (Wavemetrics, Lake Oswego, OR) and PULSE programs (Heka Elektronik).

Monitoring of Cytosolic Calcium Levels. To monitor the changes of $\left[\mathrm{Ca}^{2+}\right]_{\mathrm{c}}$, cells were plated at a density of $2 \times 10^{5}$ cells per well into 96 -well black plates, and the experiments were performed 48 hours later for BCCs or 7 days later for cortical neurons. Cells were loaded with a Krebs-HEPES solution containing $10 \mu \mathrm{M}$ fluo-4-AM and $0.2 \%$ pluronic acid. Cells were incubated for 45 minutes at $37^{\circ} \mathrm{C}$ in the dark. After this incubation period, cells were washed twice with the Krebs-HEPES solution at room temperature in the dark. Changes in fluorescence (excitation $485 \mathrm{~nm}$, emission $520 \mathrm{~nm}$ ) were measured using a fluorescent plate reader (Fluostar; BMG Labtech, Offenburg, Germany). Basal levels of fluorescence were monitored before adding the stimulation solution ( $20 \mathrm{mM}$ caffeine or $100 \mu \mathrm{M}$ histamine) with an automatic dispenser. After stimulation of the cells, changes in fluorescence were measured for 60 seconds. To normalize fluo-4 signals, responses from each well were calibrated by measuring maximum and minimum fluorescence values. At the end of each experiment, $5 \%$ Triton X-100 ( $\left.\mathrm{F}_{\text {max }}\right)$ was added, followed by $2 \mathrm{M} \mathrm{MnCl}_{2}$ $\left(\mathrm{F}_{\min }\right)$. Data were calculated as a percentage of $\mathrm{F}_{\max }-\mathrm{F}_{\text {min }}$.

Molecular Docking. Structure and conformational analysis of TBZ were acquired with the Monte Carlo method using Spartan'16 software (Wavefunction, Irvine, CA). The conformer with the lowest energy was subsequently refined with calculations based on the ab initio Hartree-Fock 6-31G** formula, and the three-dimensional structure obtained was selected for the docking studies. The structure of the binding domain of type 3 RyR was extracted from Protein Data Bank (http://www.rcsb.org; PDB ID: 4ERV) (Yuchi et al., 2012). Solvent molecules were removed from the protein. Docking calculations of TBZ on RyR were carried out using Molegro Virtual Docker in sufficiently large constrains onto the cavities found by the software, allowing the ligand to freely accommodate with the best pose. Different orientations of TBZ were reached in each cavity and ranked according to their energy scores by the MolDock Score algorithm. Among them, the pose shown in Fig. 8 represents the most highlighted one.

Chemicals. The following chemicals were used: collagenase type I, cyclopiazonic acid (CPA), 2-aminoethyldiphenyl borinate (2-APB), 
ryanodine, and TBZ were from Sigma-Aldrich (Madrid, Spain); Dulbecco's modified Eagle's medium, bovine serum albumin fraction V, fetal calf serum, and antibiotics were from Gibco (Madrid, Spain). All other chemicals used were reagent grade from Merck and Panreac Química (Madrid, Spain). CPA, 2-APB, ryanodine, and TBZ $\left(10^{-2} \mathrm{M}\right)$ were prepared in dimethylsulfoxide and protected from light. Final drug concentrations were obtained by diluting the stock solutions directly into the extracellular solution. At these dilutions, dimethylsulfoxide had no effect on the parameters studied here.

Data Analysis. Data are presented as single examples of original records to illustrate the experimental protocols and as averaged pooled data from several experiments, as means \pm S.E.M. of the number of different experiments performed (number of cell batches, $n$ ) and different cultures used (N). Mathematical analysis was done using the GraphPad Prism software, version 5.01 (GraphPad Software, La Jolla, CA). The statistical significance between groups of experiments was estimated using a nonparametric Mann-Whitney rank sum test, or one-way analysis of variance followed by the Tukey or Kruskal-Wallis post hoc test, when appropriate.

\section{Results}

Facilitation of Catecholamine Release by TBZ. Experiments were performed to test first how sequential pulsing with high $\mathrm{K}^{+}$(35 mM, 5 seconds), applied at 1minute intervals to BCCs trapped in a microchamber and perifused with Krebs-Hepes solution at $37^{\circ} \mathrm{C}$, elicited the release of catecholamines, a response that was monitored online with an electrochemical detector. An example of those responses elicited by 22 intermittent $\mathrm{K}^{+}$applications is displayed in Fig. 1A. In this experiment, the initial secretory response $(\mathrm{P} 1)$ was $210 \mathrm{nA}$; in subsequent $\mathrm{K}^{+}$ pulses, the response gradually decayed to a value of $90 \mathrm{nA}$ in P22.

In a similar experiment conducted with another batch of cells, the effect of TBZ at $3 \mu \mathrm{M}$ on $\mathrm{K}^{+}$-elicited secretory responses was tested. The drug was applied 30 seconds before
$\mathrm{P} 7$ and was perifused during the next nine $\mathrm{K}^{+}$pulses until P16. During P7 to P10, the secretory response was augmented from $220 \mathrm{nA}$ in P6 to around $260 \mathrm{nA}$ in P8 to P10; after this enhanced plateau, secretion gradually decreased to a value of $220 \mathrm{nA}$ in P16. Then, after TBZ withdrawal, the secretory response abruptly decayed to values of around $160 \mathrm{nA}$ in P17 and P18 (Fig. 1B).

Pooled data of experiments performed with the previously described protocols are graphed in Fig. 1C. Within each individual experiment, data were normalized as a percentage of $\mathrm{P} 6$, the pulse preceding the exposure of cells to TBZ. The time course of control responses (pulses P6 to P22, means \pm S.E.M. of 10 experiments from five different cultures) closely reproduces the time course of the example control experiment of Fig. 1A - namely, a gradual decay of the amplitude of secretory spike responses to $60 \%$ at P22. In the cells exposed to TBZ ( $3 \mu \mathrm{M})$, the responses are always above those of the control curve, including those that follow TBZ washout. Although the responses are only mildly enhanced by TBZ (26\% above control, at P8), they are statistically significant (Fig. 1C).

Concerning the concentration-response relationship of the effects of TBZ on $\mathrm{K}^{+}$-elicited secretion, we found that at 1 and $3 \mu \mathrm{M}$, the drug exhibited a facilitatory action $(109.9 \% \pm$ $1.9 \%$ and $125.9 \% \pm 5.4 \%$, with respect to control response). However, at $10 \mu \mathrm{M}, \mathrm{TBZ}$ caused a mild inhibition (Fig. 1D).

Interactions of Tetrabenazine with BayK8644 and Nifedipine. Catecholamine release from adrenal medullary CCs absolutely depends on the presence of $\mathrm{Ca}^{2+}$ ions in the extracellular milieu while the $\mathrm{K}^{+}$depolarizing stimulus is applied (Douglas and Rubin, 1963). Exocytosis is triggered when the extracellular $\mathrm{Ca}^{2+}$ entering the cell through VACCs is abruptly increased at subplasmalemmal sites near the exocytotic machinery (Baker and Knight, 1978; Neher, 1998). Bovine CCs express L-subtype ( $\alpha_{1 \mathrm{D}}$, Cav1.3), $\mathrm{N}$-subtype ( $\left.\alpha_{2 \mathrm{~B}}, \mathrm{Cav} 2.2\right)$, and PQ-subtype ( $\alpha_{2 \mathrm{~A}}$, Cav2.1) of VACCs (García et al., 2006). All channels contribute to providing the necessary $\mathrm{Ca}^{2+}$ for exocytosis; however,
A
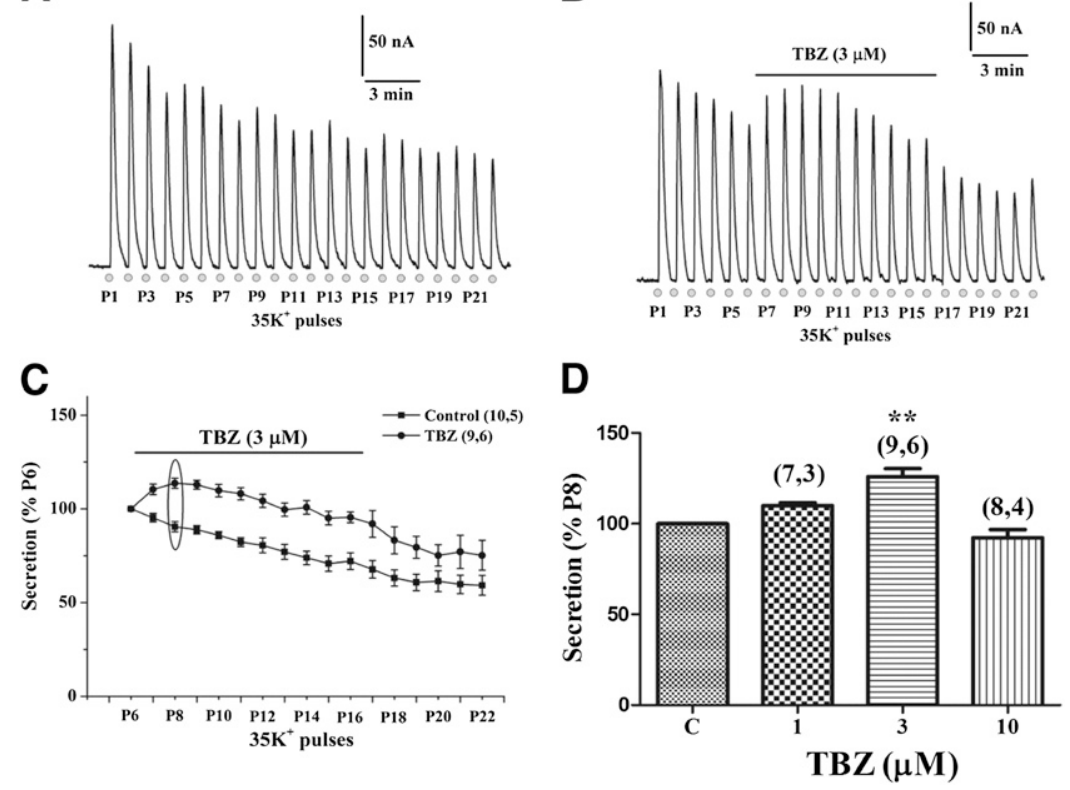

Fig. 1. Facilitation of exocytosis by TBZ. BCCs $\left(5 \times 10^{6}\right)$ trapped in a microchamber were constantly perifused with Krebs-HEPES at $37^{\circ} \mathrm{C}$. After an initial equilibration period to get a stable baseline amperometric recording, cells were intermittently stimulated at 1-minute intervals with 5 -second pulses of a solution enriched in $\mathrm{K}^{+}(35 \mathrm{mM}$, isosmotic reduction of $\left.\mathrm{Na}^{+}\right)$. Secretion of catecholamines was amperometrically monitored online and expressed in nanoamperes of current generated by oxidized amines [calibration bars in (A) and (B)]. (A) Example control experiment showing the secretory spike responses produced by 22 sequential $\mathrm{K}^{+}$pulses. (B) Example experiment of secretory responses elicited by sequential $\mathrm{K}^{+}$pulses before, during, and after cell perifusion with $3 \mu \mathrm{M}$ TBZ (top horizontal line). (C) Averaged pooled data of experiments performed with the same protocols as those shown in (A) and (B); data in nanoamperes were normalized within each individual experiment as a percentage of $\mathrm{P} 6$ (ordinate). (D) Effects of various concentrations of TBZ (abscissa) on the $\mathrm{K}^{+}$secretory responses; normalized data with resped $\mathrm{K}^{+}$pulse P8 are plotted. Data in (C) and (D) are means \pm S.E.M. of the number of cell batches (first number in parentheses) and cultures from different glands and days (second number in parentheses). $* * P<0.01$ with respect to control (one-way ANOVA with post hoc Kruskal-Wallis analysis). 
L-subtype channels make a large contribution to $\mathrm{K}^{+}$elicited secretion in BCCs that is facilitated by dihydropyridine (DHP) BayK8644 (BayK) and blocked by DHP nifedipine (García et al., 1984). Thus, we tested next the effects of these two DHPs on $\mathrm{K}^{+}$-elicited secretion as well as on the facilitation of such response by TBZ.

Once more, we performed experiments of the type shown in Fig. 1. Normalized secretion (expressed as percentage of $\mathrm{P} 1$ in each separate batch of cells) is plotted in Fig. 2A, showing the decay of $\mathrm{K}^{+}$-elicited secretion in control cells, the drastic augmentation elicited by $1 \mu \mathrm{M}$ BayK, and the milder increase elicited by $3 \mu \mathrm{M}$ TBZ. The responses in the presence of BayK decayed rapidly toward control levels after its washout, in contrast to the responses after TBZ removal that decayed more slowly. Pooled data of peak responses (those indicated by the ellipse in Fig. 2A) are graphed in Fig. 2B. BayK nearly doubled the $\mathrm{K}^{+}$secretory response $(83.34 \% \pm 6.1 \%)$ while TBZ augmented it by $38.05 \% \pm 2.6 \%$.

Interactions between TBZ and DHPs were explored next. Figure 2C shows the drastic increase of secretion elicited by combined TBZ and BayK ( 3 and $1 \mu \mathrm{M}$, respectively); note that there was a combined tendency for the response to continue growing in the successive $\mathrm{K}^{+}$pulses. If $3 \mu \mathrm{M}$ nifedipine was added to cells previously being exposed to TBZ, the responses decreased drastically. Averaged pooled data (ellipse in Fig. 2C) on these different treatments are graphed in Fig. 2D. TBZ augmented the $\mathrm{K}^{+}$secretory responses by $45.3 \% \pm 8.9 \%(n=9)$; this response was reduced by nifedipine to $45.3 \% \pm 4 \%$ of the initial control $(n=6)$. On the other hand, combined BayK and TBZ caused a doubling of the response, a value similar to that obtained with BayK alone $(87.7 \% \pm$ $10.05 \%$ ) (Fig. 2B). Once again we can see that the differences between the two treatments $(42.4 \%)$, TBZ only and the combination of TBZ plus BayK, suggest that their effects do not follow the same mechanism of action.

Effects of TBZ on Sodium and Calcium Currents. The experiments in Fig. 2 suggested that the enhancing effects of secretion elicited by TBZ could have an underlying BayK-like mechanism-that is, the prolongation of opening time of L-subtype channels with enhanced $\mathrm{Ca}^{2+}$ entry occurring during a depolarizing stimulus (Cena et al., 1989). In BCCs, BayK is known to augment $\mathrm{Ca}^{2+}$ entry to enhance secretion; also, the DHP augments the L-subtype component of the whole-cell $\mathrm{Ca}^{2+}$ current $\left(\mathrm{I}_{\mathrm{Ca}}\right)$ of these cells (García et al., 2006). Hence, we tested next the effects of TBZ on $I_{\mathrm{Ca}}$.

Cells were voltage clamped at $-80 \mathrm{mV}$, and $50-\mathrm{ms}$ depolarizing pulses were applied at 30 -second intervals to generate maximal peak $\mathrm{I}_{\mathrm{Ca}}$ currents (Fenwick et al., 1982). Figure 3A shows a control current composed of initial fast inactivating peak current that corresponds to $\mathrm{Na}^{+}$current $\left(\mathrm{I}_{\mathrm{Na}}\right.$; trace expanded) and an ensuing slow current that was stable upon the application of repeated pulses to $0 \mathrm{mV}$ given at 30 -second intervals, the $\mathrm{Ca}^{2+}$ current $\left(\mathrm{I}_{\mathrm{Ca}}\right)$. Quantitative pooled data on peak $\mathrm{I}_{\mathrm{Na}}$ (trace expanded) currents indicate that TBZ did not affect such current (Fig. 3B). When $3 \mu \mathrm{M}$ TBZ was perifused, the blockade was nearly completely reversed upon TBZ washout (Fig. 3A). The degree of blockade was monitored at the initial peak current; in eight cells from three different cultures, peak $\mathrm{I}_{\mathrm{Ca}}$ was blocked $12.7 \% \pm 0.5 \%$ (paired $t$ test, $\mathrm{t}=7.528, P=0.0001$ ) by $3 \mu \mathrm{M}$ TBZ (Fig. $3 \mathrm{C}$ ).
A

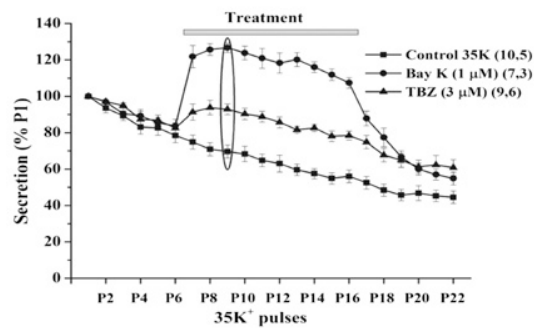

C

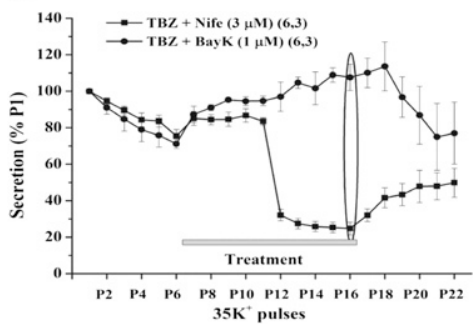

B

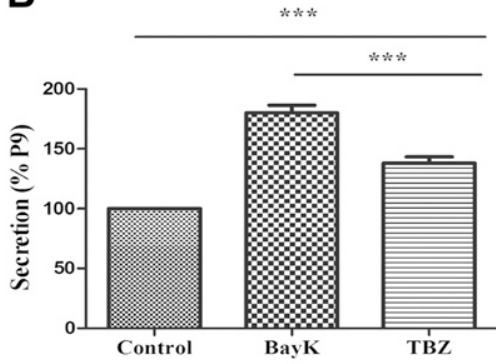

D

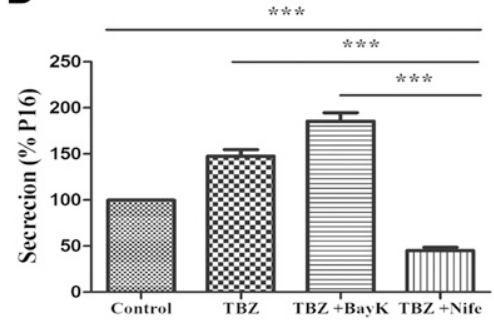

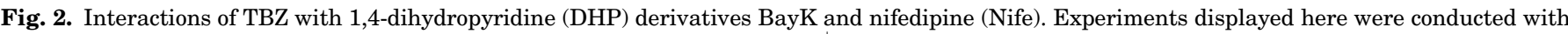

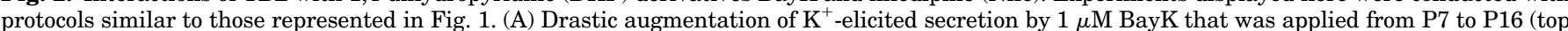

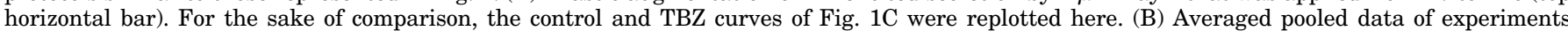

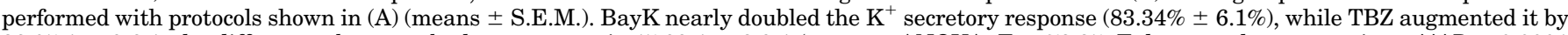

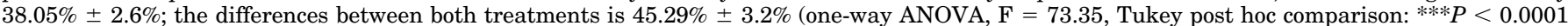

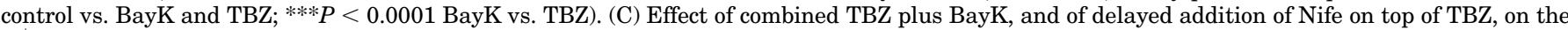

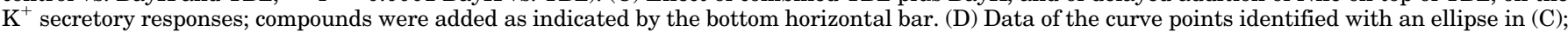

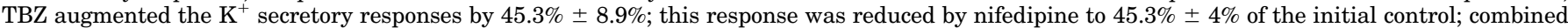

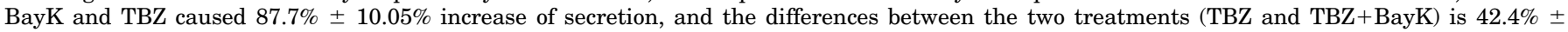

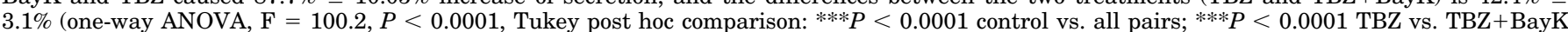

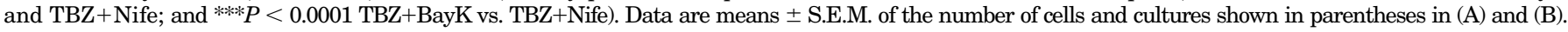


A

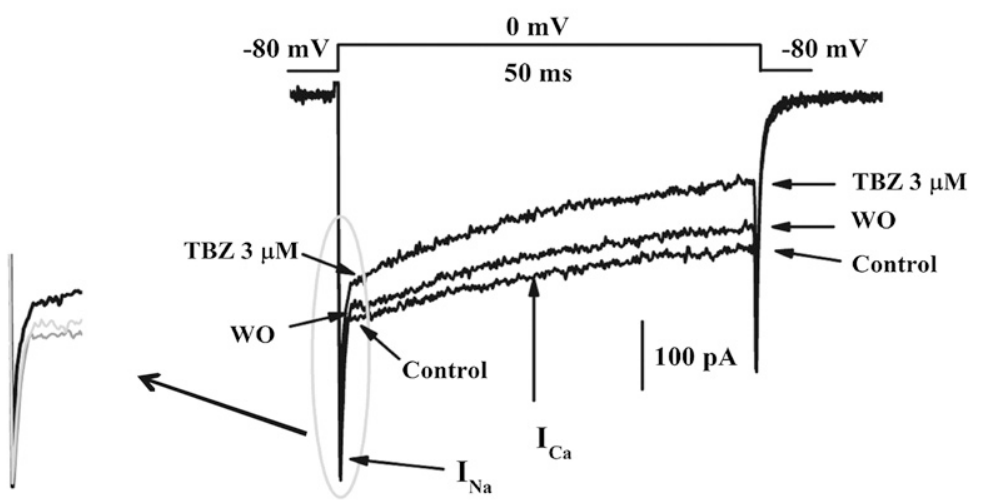

B

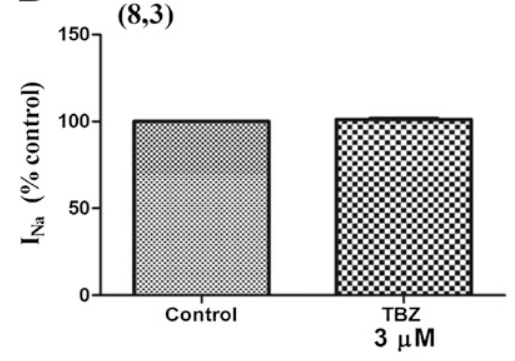

C

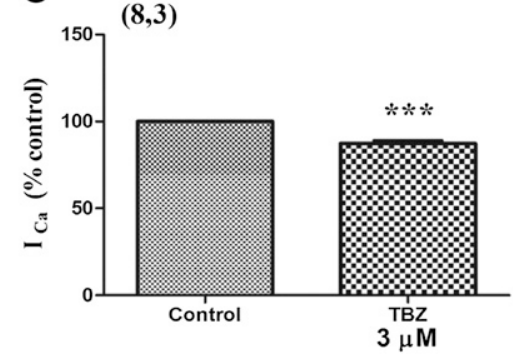

Fig. 3. Mild blockade of calcium currents, but not sodium currents, elicited by TBZ. Whole-cell inward $\mathrm{Na}^{+}\left(\mathrm{I}_{\mathrm{Na}}\right)$ and $\mathrm{Ca}^{2+}$ currents $\left(\mathrm{I}_{\mathrm{Ca}}\right)$ were explored in voltage-clamped BCCs under the whole-cell configuration of the patch-clamp technique. Calcium at $2 \mathrm{mM}$ was used as a charge carrier. The initial fast inactivating $\mathrm{I}_{\mathrm{Na}}$ (extended area) and the ensuing slow inactivating $\mathrm{I}_{\mathrm{Ca}}$ are identified by arrows in (A). Currents were elicited by 50-ms depolarizing pulses to $0 \mathrm{mV}$ applied at 30 -second intervals [protocol on top of (A)]. Upon breaking into the cell with the patch pipette, various pulses were given to stabilize the current. Subsequently, TBZ was applied, and 30 seconds thereafter four pulses were applied (total of 120 seconds with drug); finally, the drug was removed to allow current recovery. (A) Example $\mathrm{I}_{\mathrm{Na}}\left(\operatorname{arrow} \mathrm{I}_{\mathrm{Na}}\right.$ ) and $\mathrm{I}_{\mathrm{Ca}}$ traces (arrow $\mathrm{I}_{\mathrm{Ca}}$ ) before (control), during cell exposure to TBZ, and after TBZ withdrawal in a cell stimulated with 50-ms pulses. (B) Pooled normalized data within each cell explored as percentage of the initial control $\mathrm{I}_{\mathrm{Na}}$ amplitude. (C) Pooled normalized data within each cell explored as percentage of the initial control $\mathrm{I}_{\mathrm{Ca}}$ amplitude; TBZ (3 $\left.\mu \mathrm{M}\right)$ was blocked $12.7 \% \pm$ $0.5 \%$ (paired test, $\mathrm{t}=7.528, P=0.0001$ ). Data in (B) and (C) are means \pm S.E.M. of the number of cells and cultures shown in parentheses.
Effects of TBZ on Secretion Elicited by Caffeine or Histamine Pulses. At the $\mathrm{ER} \mathrm{Ca}^{2+}$ store, two mechanisms have been implicated in the release of $\mathrm{Ca}^{2+}$ into the cytosol. This has been directly proven using $\mathrm{Ca}^{2+}$-sensitive aequorins targeted to the ER lumen. On the one hand, upon stimulation with caffeine, $\mathrm{Ca}^{2+}$ release occurred through ryanodine receptors; on the other hand, histamine also elicited $\mathrm{Ca}^{2+}$ release but through inositol 1,4,5-trisphosphate receptor $\left(\mathrm{IP}_{3} \mathrm{R}\right)$ channels (Alonso et al., 1999). Thus, we thought it interesting to discern whether the secretory responses elicited with repeated pulses of caffeine or histamine were affected by tetrabenazine, as those of $\mathrm{K}^{+}$were.

In BCCs, caffeine pulses trigger catecholamine release responses linked to $\mathrm{ER} \mathrm{Ca}^{2+}$ release through RyRs (Cheek et al., 1990); when repeatedly applied onto the same batch of cells, those responses undergo rapid inactivation because the $\mathrm{ER} \mathrm{Ca}^{2+}$ store is gradually emptied (Lara et al., 1997). It seemed to us that this protocol could be used here to find out whether TBZ was affecting such responses.

A protocol similar to that used with $\mathrm{K}^{+}$pulses (Fig. 1, A and B) was designed to test the secretory responses of BCCs challenged with 5-second pulses of $20 \mathrm{mM}$ caffeine, applied at 1-minute intervals to the same batch of cells (22 pulses). An original amperometric record of the sequential secretion responses is displayed in Fig. 4A. The initial sharp response of $263 \pm 34.3 \mathrm{nA}$ was halved in P2; in subsequent pulses, the responses underwent a gradual decay to reach a plateau at a level of secretion that was only $25 \%-30 \%$ at caffeine pulses 15-22. In a different cell batch, cells were similarly challenged with 22 caffeine pulses; between pulses P7 and P16, $3 \mu \mathrm{M}$ TBZ was introduced into the cell superfusion system. In the original example record of Fig. 4B, the responses decayed from $273 \mathrm{nA}$ in $\mathrm{P} 1$ to $111.2 \mathrm{nA}$ in P6. From P7 onward, cell exposure to TBZ modified the responses in two ways: 1) a prompt augmentation of secretory spiked to about $163.2 \mathrm{nA}$ (P9), and
2) the decay of responses was prevented. Upon TBZ removal, the responses quickly faded to $79.5 \mathrm{nA}$ in pulse P22.

Through the stimulation of $\mathrm{H}_{1}$ receptors, histamine also elicits the secretion of catecholamines by stimulating the release of $\mathrm{ER} \mathrm{Ca}{ }^{2+}$ via $\mathrm{IP}_{3} \mathrm{Rs}_{\mathrm{S}}$ into the cytosol (Cheek et al., 1994; de Pascual and García, 2007; Milla et al., 2011). Thus, experiments similar to those performed with caffeine were carried out by challenging the cells with 5-second pulses of $100 \mu \mathrm{M}$ histamine. The example record in Fig. 4C shows the fast gradual decay of the histamine-elicited secretory responses, likely due to $\mathrm{H}_{1}$ receptor desensitization. The example trace in Fig. 4D was taken from a similar experiment in which TBZ was applied at pulses P7 to P16; the drug did not affect the decay of histamine secretory responses at all.

Pooled data from five to eight experiments conducted in three to four cell cultures in cells challenged with caffeine or histamine are graphed in Fig. 4, E and F. Normalized overlapping curves on pulse number versus secretion responses indicated a very close time course of secretion decay in both cells challenged with caffeine or histamine (Fig. 4E). On the other hand, pooled data indicate that while TBZ augmented and maintained stabilization of the caffeine secretory responses, the histamine responses were unaffected by the drug. The maximum increase occurred with caffeine at P9 $(28.04 \% \pm 2.03 \% ; n=6, P<0.001)$. In five experiments, TBZ did not affect the histamine-evoked secretion (Fig. 4F).

Pharmacological Manipulation of the ER Calcium Store and Its Effect on Caffeine and Histamine Secretory Responses. To test whether the effects of TBZ on the secretory responses of cells challenged with caffeine or histamine were linked to the $\mathrm{ER}^{\mathrm{Ca}^{2+}}$ store, we pharmacologically intervened on such store at three ionic receptor sites: inhibition of sarco-endoplasmic reticulum calcio ATPase 
A

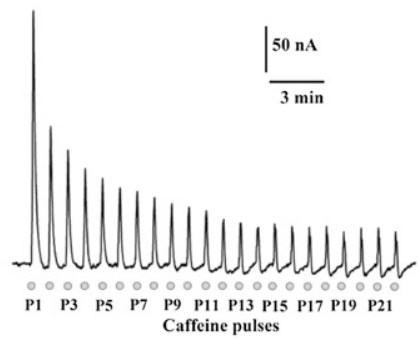

C

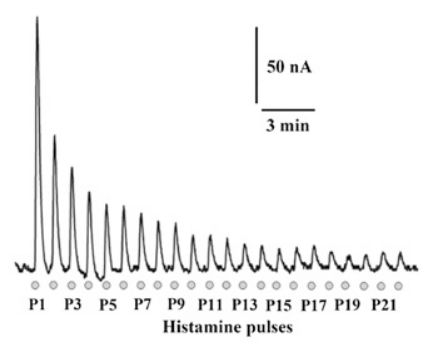

E

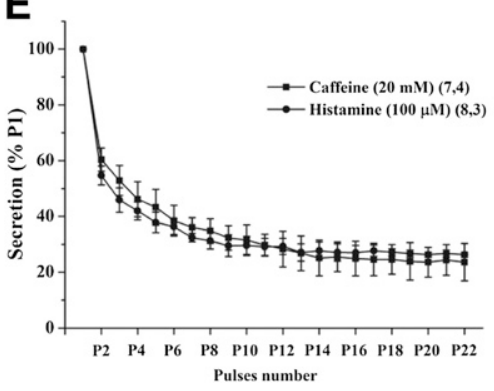

B

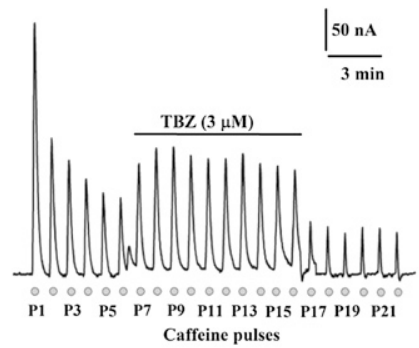

D
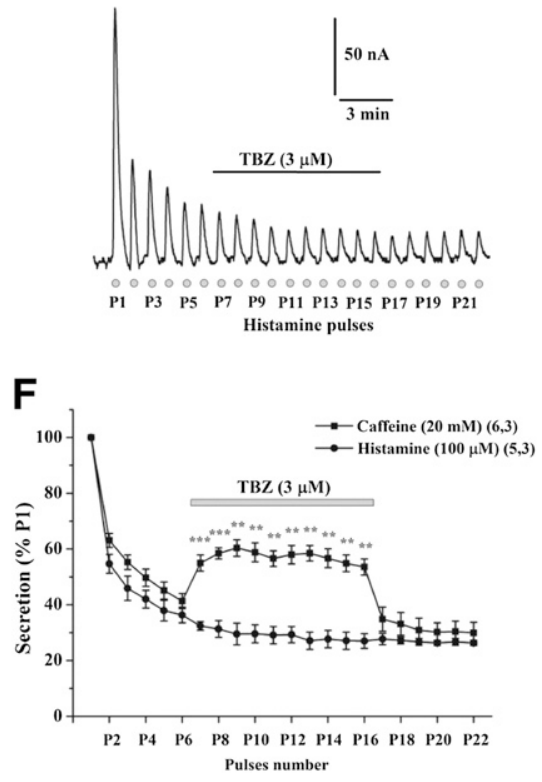

Fig. 4. Whereas the secretory responses to caffeine pulsing were enhanced by TBZ, those of histamine were unaffected. Experimental protocols are similar to those of Fig. 1, but here cells were challenged with 5 -second pulses of $20 \mathrm{mM}$ caffeine or $100 \mu \mathrm{M}$ histamine, applied at 1-minute intervals. (A) Original example record of the secretory responses elicited by caffeine (pulses P1 to P22 in the abscissa; secretory responses in nanoamperes per pulse, calibration bars). (B) As in (A) but $3 \mu \mathrm{M}$ TBZ was cell perifused during caffeine pulses P7 to P16. (C) Cells challenged with 5-second pulses of $100 \mu \mathrm{M}$ histamine applied at 1-minute intervals. (D) A similar experiment with histamine pulses and cell exposure to TBZ at pulses $\mathrm{P} 7$ to P16. (E) Pooled data of control experiments performed with caffeine or histamine; data are normalized as percentage of $\mathrm{P} 1$ within each individual experiment. (F) Pooled data from experiments on cell stimulation with caffeine or histamine, and introduction of TBZ as indicated. In the case of caffeine, maximum enhanced secretion by TBZ was achieved at P8 $(28.04 \% \pm 2.03 \%)$, and the lowest increase was at pulse P16 (21.22 \pm 1.89$)$. Mann-Whitney no parametric test: $* * * P=0.0006$; $* * P=0.0043$. Data on pulse secretion are means \pm S.E.M. of the individual number of experiments and cell cultures shown in parentheses.
(SERCA) with CPA (Goeger et al., 1988; Seidler et al., 1989), inhibition of the RyR with ryanodine (Fleischer et al., 1985; Pessah et al., 1986; Lattanzio et al., 1987), or blockade of the $\mathrm{IP}_{3} \mathrm{R}$ channel with 2-APB (Maruyama et al., 1997); these interventions are known to deplete the $\mathrm{ER} \mathrm{Ca}^{2+}$ store, but through different mechanisms. Thus, experiments with protocols similar to those described earlier with caffeine and histamine were conducted.

Figure 5A shows that CPA caused a sharp decrease of the caffeine responses (with or without TBZ) with a very fast time course; upon CPA washout, the responses recovered to the expected control level. Ryanodine $(10 \mu \mathrm{M})$ also elicited a prompt secretion decrease of the caffeine responses applied in the presence or absence of TBZ. Data are quantitatively expressed in Fig. 5B. The data on TBZ-elicited enhanced secretion are normalized as a percentage of control (P9) and were calculated from the experiments of Fig. 4. In the presence of CPA, TBZ $+\mathrm{CPA}$, ryanodine, or TBZ+ryanodine, the caffeine secretory responses were drastically decreased by $69.3 \% \pm 3.2 \%, 65.3 \% \pm 5.1 \%$, $84.3 \% \pm 3.1 \%$, and $90.2 \% \pm 1.3 \%$, respectively (Fig. $5 \mathrm{~B}$ ).

Experiments with histamine pulses also showed a pronounced inhibition of secretion responses in the presence of $\mathrm{CPA}(44.2 \% \pm 3.2 \%), \mathrm{TBZ}+\mathrm{CPA}(43.2 \% \pm 3.2 \%), 2-\mathrm{APB}$ $(84.7 \% \pm 4.5 \%)$, and TBZ+2-APB $(88.5 \% \pm 4.2 \%)$ (Fig. $5, \mathrm{C}$ and $\mathrm{D})$. Thus, these experiments provide proof that the secretory responses of caffeine and histamine, when applied either alone or in the presence of TBZ, are mediated by $\mathrm{Ca}^{2+}$ release from the $\mathrm{ER} \mathrm{Ca}^{2+}$ store. They also indicate that TBZ may be selectively acting on the RyR calcium channel of the ER.

Effects of TBZ on the Cytosolic Elevations of Calcium Elicited by Caffeine or Histamine. That caffeine triggers $\mathrm{ER} \mathrm{Ca}^{2+}$ release into the cytosol of BCCs through RyRs has been indirectly studied with cytosolic $\mathrm{Ca}^{2+}$ fluorescence probes (Cheek et al., 1990, 1993) and directly studied with ER-targeted aequorins (Alonso et al., 1999). Similar approaches have been used to study the release of $\mathrm{ER} \mathrm{Ca}^{2+}$ through $\mathrm{IP}_{3} \mathrm{Rs}$ of BCCs (Stauderman and Pruss, 1990; Artalejo et al., 1993; Alonso et al., 1999). Here, we studied the effects of TBZ on ER $\mathrm{Ca}^{2+}$ release through RyRs (caffeine) or $\mathrm{IP}_{3} \mathrm{Rs}_{\mathrm{s}}$ (histamine) in populations of BCCs loaded with fluo-4.

Cells were incubated at $37^{\circ} \mathrm{C}$ in the dark with $\mathrm{TBZ}$ at 1-10 $\mu \mathrm{M}$, with ryanodine $(10 \mu \mathrm{M})$, or with combined Rya+TBZ. Figure 6 A shows example traces of the time course of $\left[\mathrm{Ca}^{2+}\right]_{\mathrm{c}}$ elevations triggered by $20 \mathrm{mM}$ caffeine. In control cells, there was a rapid $\left[\mathrm{Ca}^{2+}\right]_{\mathrm{c}}$ elevation that gradually faded off surely because the ER $\mathrm{Ca}^{2+}$ was being depleted and the cytosolic $\mathrm{Ca}^{2+}$ elevations are cleared by mitochondria and by plasmalemmal $\mathrm{Ca}^{2+}$ efflux pumps (Alonso et al., 1999; Villalobos et al., 2002). In the presence of TBZ at 1, 3, and $10 \mu \mathrm{M}$, the caffeine-elicited $\mathrm{Ca}^{2+}$ elevations were notably augmented, and although the $\left[\mathrm{Ca}^{2+}\right]_{\mathrm{c}}$ transient also faded off 

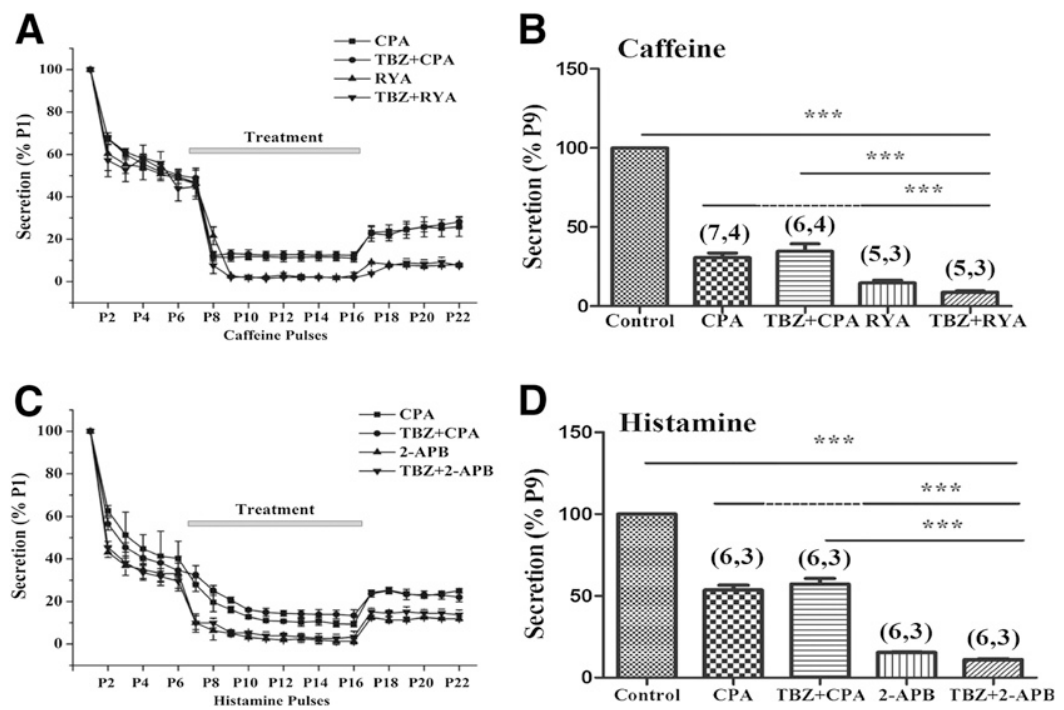

Fig. 5. Calcium depletion of the ER by SERCA inhibition with $5 \mu \mathrm{M}$ CPA depresses the secretory responses to caffeine or histamine. (A) Time course of secretory responses to sequential caffeine pulses ( $20 \mathrm{mM}$ caffeine, for 5 seconds, applied at 1-minute intervals); drugs [CPA and TBZ at $3 \mu \mathrm{M}$, ryanodine (RYA) at $10 \mu \mathrm{M}$ ] were applied from pulses 7 to 16 (top horizontal bar). (B) In the presence of CPA, TBZ+CPA, RYA, or TBZ+RYA, the caffeine secretory responses were drastically decreased by $69.3 \% \pm 3.2 \%, 65.3 \% \pm 5.1 \%, 84.3 \% \pm 3.1 \%$, and $90.2 \% \pm 1.3 \%$, respectively (one-way ANOVA, $\mathrm{F}=198.7, P<0.0001$; Tukey post hoc comparison: $* * * P<0.0001$ control vs. all pairs; $* * * P<0.0001 \mathrm{TBZ}$ vs. RYA and TBZ+RYA; and $* * * P<0.0001 \mathrm{CPA}$ vs. TBZ+CPA, RYA, and TBZ+RYA). (C) Time course of secretory responses elicited by sequential pulses of histamine (100 $\mu \mathrm{M}$ for 5 seconds applied at 1-minute intervals) and the effects of various compounds (CPA and 2-APB at $10 \mu \mathrm{M}$ ) on those responses, added from pulses P7 to P16 (top horizontal bar). (D) The histamine secretory responses were decreased in the presence of $\mathrm{CPA}(44.2 \% \pm 3.2 \%)$, TBZ $+\mathrm{CPA}(43.2 \% \pm 3.2 \%), 2-\mathrm{APB}(84.7 \% \pm 4.5 \%)$, and TBZ+2-APB $(88.5 \% \pm 4.2 \%)($ oneway ANOVA, $\mathrm{F}=321.6, P<0.0001$; Tukey post hoc comparison: $* * * P<0.0001$ control vs. all pairs; $* * P<0.0001 \mathrm{CPA}$ vs. 2 -APB and TBZ+2-APB; and *** $P<0.0001 \mathrm{TBZ}+\mathrm{CPA}$ vs. 2-APB and TBZ $+2-\mathrm{APB}$ ). (B and D) Averaged pooled data normalized as percentage of P9 (control response); data correspond to pulse P9. Data in (B) and (D) are means \pm S.E.M. of the number of cell batches (n) and cultures (N), shown in parentheses on top of each column.

gradually, the $\left[\mathrm{Ca}^{2+}\right]_{\mathrm{c}}$ was higher at the end of the recording period (60 seconds) with respect to control. On quantitative terms, the peak $\left[\mathrm{Ca}^{2+}\right]_{\mathrm{c}}$ elevations were augmented more than twice in the presence of 1,3 , and $10 \mu \mathrm{M} \mathrm{TBZ}(228.4 \% \pm 26.4 \%$, $197.3 \% \pm 17.4 \%$, and $236.8 \% \pm 27.2 \%$, respectively) (Fig. 6B). Obviously, in the presence of ryanodine, which causes full depletion of $\mathrm{ER} \mathrm{Ca}^{2+}$ (Alonso et al., 1999), either alone or combined with TBZ, the caffeine response was abolished $(7.68 \% \pm 3.08 \%$ and $5.72 \% \pm 2.6 \%$, respectively) (Fig. 6, A and B).

Experiments with protocols similar to those of caffeine were done using histamine. Figure $6 \mathrm{C}$ shows a family of $\left[\mathrm{Ca}^{2+}\right]_{\mathrm{c}}$ elevation curves triggered by histamine $(100 \mu \mathrm{M})$ applied in the absence (control) and presence of the various treatments (protocols similar to those used in the caffeine experiments). These histamine-triggered $\mathrm{Ca}^{2+}$ signals differed from those of caffeine in two aspects: 1 ) the peak $\left[\mathrm{Ca}^{2+}\right]_{\mathrm{c}}$ elevation was smaller, and 2) the decay of $\left[\mathrm{Ca}^{2+}\right]_{c}$ was very slow. This could find an explanation in the fact that the mitochondrial $\mathrm{Ca}^{2+}$ uniporter has a low affinity for $\mathrm{Ca}^{2+}$; if the histamine $\mathrm{Ca}^{2+}$ elevation is lower, mitochondria may not see such local $\left[\mathrm{Ca}^{2+}\right]_{\mathrm{c}}$, and hence, the $\mathrm{Ca}^{2+}$ clearance will take place only at the expense of the low-rate plasmalemmal $\mathrm{Ca}^{2+}$ pumps (Villalobos et al., 2002). Another drastic difference of histamine responses in comparison with those of caffeine is the fact that TBZ at $1-10 \mu \mathrm{M}$ did not affect the $\left[\mathrm{Ca}^{2+}\right]_{\mathrm{c}}$ elevations triggered by histamine (Fig. 6, C and D). As expected, the blocker of $\mathrm{IP}_{3} \mathrm{R} 2$ 2-APB (at $10 \mu \mathrm{M}$ ) alone or combined with TBZ abolished the histamine responses $(3.63 \% \pm 3.1 \%$ and $0.04 \% \pm$ $4.7 \%$, respectively) (Fig. 6, C and D).

Effects of TBZ on the $\left[\mathrm{Ca}^{2+}\right]_{\mathrm{c}}$ Elevations Triggered by Caffeine or Histamine in Cortical Neurons. The proof of concept in which TBZ is used to treat the HD-associated chorea symptoms is based on its ability to inhibit VMAT2 at central dopaminergic neurons. Therefore, we considered it of interest to explore whether TBZ was also targeting RyRs (and not $\mathrm{IP}_{3} \mathrm{Rs}$ ) in primary cultures of rat embryo cortical neurons. Thus, experiments similar to those performed with BCCs (Fig. 6) were conducted in neurons loaded with fluo-4.

Figure 7A shows a family of traces of the $\left[\mathrm{Ca}^{2+}\right]_{c}$ elevations triggered by caffeine in control neurons and in neurons previously exposed to TBZ $(1-10 \mu \mathrm{M})$, ryanodine $(10 \mu \mathrm{M})$, or combined ryanodine+TBZ. The control $\mathrm{Ca}^{2+}$ signal reached a peak and then a gradual decay followed. In the presence of TBZ, the peak was more than doubled and also decayed to reach the control $\left[\mathrm{Ca}^{2+}\right]_{\mathrm{c}}$ level by the end of the 60 -second recording period. Pooled results using this protocol are graphed in Fig. 7B. Note the augmentation by TBZ (1, 3, and $10 \mu \mathrm{M})$ of the caffeine-elicited $\mathrm{Ca}^{2+}$ signal $(219.2 \% \pm 22.3 \%$, $214.6 \% \pm 24.7 \%$, and $218.7 \% \pm 33 \%$, respectively) and the abolition of the responses by ryanodine, alone or combined with TBZ $(2.53 \% \pm 10.9 \%$ and $4.58 \% \pm 7.6 \%$, respectively).

The family of $\left[\mathrm{Ca}^{2+}\right]_{\mathrm{c}}$ traces displayed in Fig. $7 \mathrm{C}$ were generated by histamine in the absence (control) or presence of the different treatments. Of note is the very mild decay of the response in contrast to caffeine. This graph and pooled data of Fig. 7D show that TBZ did not modify the histamine-elicited $\left[\mathrm{Ca}^{2+}\right]_{\mathrm{c}}$ elevations. They also show that 2-APB alone or combined with TBZ abolished the histamine-evoked responses $(8.72 \% \pm 11 \%$ and $2.01 \% \pm 1.95 \%$, respectively $)$

Molecular Docking Study of TBZ Coupling with the Ryanodine Receptor. An explanation of the pharmacological mechanism observed with TBZ could be that it directly interacts with the RyR. A prediction of such interaction may be appreciated by molecular docking analysis using the X-ray structure of the type 3 RyR deposited in the Protein Data Bank (http://www.rcsb.org; PDB ID: 4ERV) (Yuchi et al., 2012). The 
A

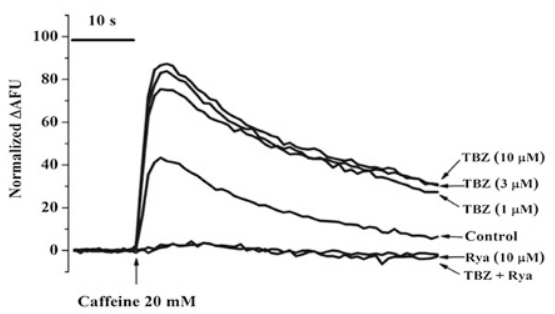

C

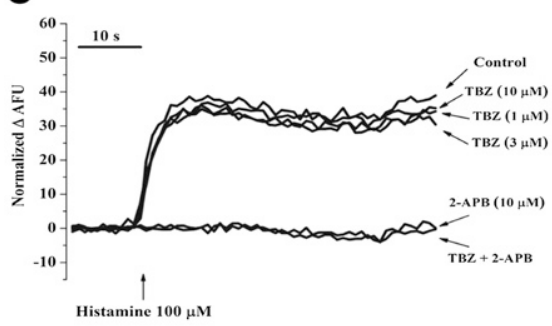

B
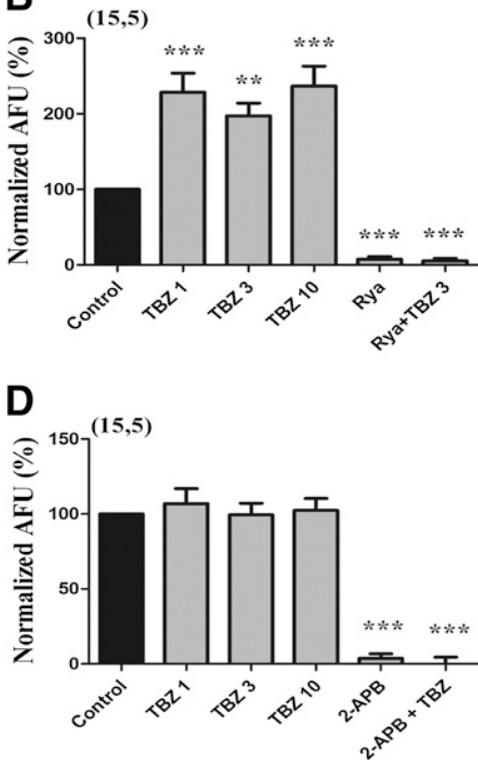

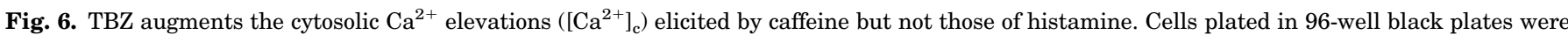

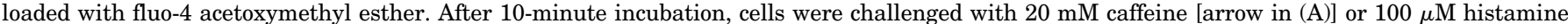

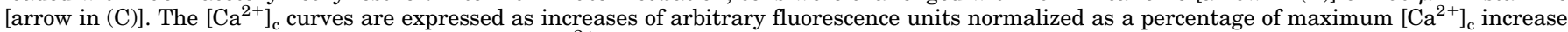

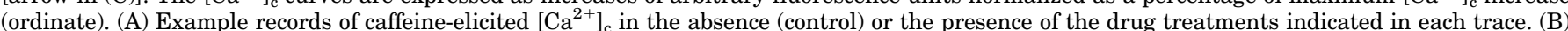

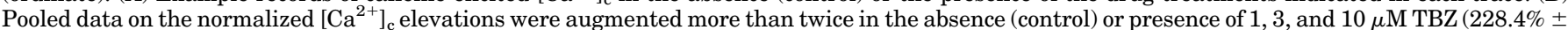

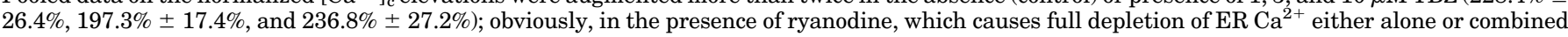

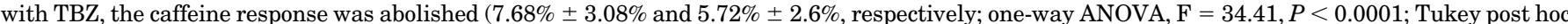

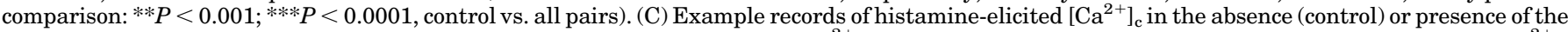

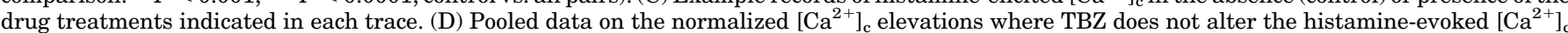

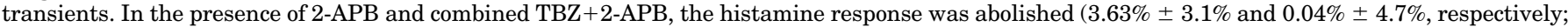

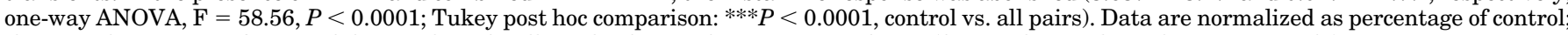
they are the means \pm S.E.M. of the number of wells and cultures shown in parentheses (first and second number, respectively).

complex TBZ-RyR with the lowest energy occurred where RyR posed in a binding pocket located at the $\mathrm{RyR} \mathrm{Ca}^{2+}$-binding domain (Fig. 8A), connected to several amino acids by hydrogen bonds $(2.20 \AA$ with Arg 2599 and $2.94 \AA$ with the skeleton NH of Leu 2721) and by van der Waals interactions with Ala 2749 and Lys 2703 (Fig. 8B).

\section{Discussion}

The central finding in this investigation is the facilitation of the catecholamine release responses elicited by TBZ in BCCs challenged with sequential brief $\mathrm{K}^{+}$pulses. As these responses depend on $\mathrm{Ca}^{2+}$ entry through VACCs (Douglas and Rubin, 1963; García et al., 2006; Mahapatra et al., 2012), their facilitation by TBZ could be due to an augmented $\mathrm{Ca}^{2+}$ entry through VACCs. As BCCs express the L-subtype (20\%), N-subtype (30\%), and PQ-subtype (50\%) of VACCs, enhanced $\mathrm{Ca}^{2+}$ entry could be associated with a selective effect of TBZ on one of those channel subtypes. Under conditions of BCC depolarization with high $\mathrm{K}^{+}$concentrations for several seconds, the $\mathrm{N}$ - and $\mathrm{PQ}$-subtype channels undergo fast inactivation in comparison with slower L-subtype channel inactivation (Villarroya et al., 1999; Hernández-Guijo et al., 2001); this explains why $\mathrm{K}^{+}$-elicited secretion from BCCs is mostly triggered by $\mathrm{Ca}^{2+}$ entry through L-subtype channels and that this response is augmented by BayK, which delays channel inactivation and is blocked by nifedipine and other dihydropyridine derivatives (García et al., 1984). As expected, BayK enhanced and nifedipine diminished the $\mathrm{K}^{+}$-elicited secretory responses independently of the presence or absence of TBZ (Fig. 2), indicating that facilitation of secretion by TBZ could be due to either enhanced $\mathrm{Ca}^{2+}$ entry through VACCs or $\mathrm{Ca}^{2+}$ mobilization from intracellular $\mathrm{Ca}^{2+}$ stores. We can discard the first option on the basis that TBZ did not augment $\mathrm{I}_{\mathrm{Ca}}$; on the contrary, the drug caused a mild current inhibition (Fig. 3)

That the ER $\mathrm{Ca}^{2+}$ store contributes to the shaping of the $\left[\mathrm{Ca}^{2+}\right]_{\mathrm{c}}$ transients and the secretory responses in BCCs has been proven with different experimental approaches. The most conspicuous has been the depletion of the ER $\mathrm{Ca}^{2+}$ store with the SERCA blocker thapsigargin, which depresses the depolarization-evoked secretory responses in BCCs (Nowicky and Duchen, 1998; Pan and Fox, 2000; Cuchillo-Ibáñez et al., 2002). This is consonant with other experimental approaches showing that challenging of BCCs with repeated caffeine pulses causes secretory responses by $\mathrm{ER} \mathrm{Ca}^{2+}$ release through $\mathrm{RyRs}$, which inactivate as the $\mathrm{ER} \mathrm{Ca}^{2+}$ store is emptied; additionally, the $\mathrm{K}^{+}$secretory responses are also decreased upon caffeine challenging (Lara et al., 1997). This is in agreement with the observation that the $\mathrm{K}^{+}$challenging of BCCs transfected with ER-targeted aequorin causes an $\mathrm{ER} \mathrm{Ca}^{2+}$ decrease, which is direct proof of the presence of $\mathrm{Ca}^{2+}$-induced $\mathrm{Ca}^{2+}$ release (CICR) (Alonso et al., 1999); this is proof that this CICR mechanism contributes to the augmentation of $\mathrm{K}^{+}$ secretory responses, likely due to more sustained $\left[\mathrm{Ca}^{2+}\right]_{\mathrm{c}}$ elevations in depolarized BCCs. Here comes our hypothesis in the present study in the sense that TBZ could facilitate the $\mathrm{K}^{+}$secretory responses through the higher or more prolonged activation of the CICR mechanism. 

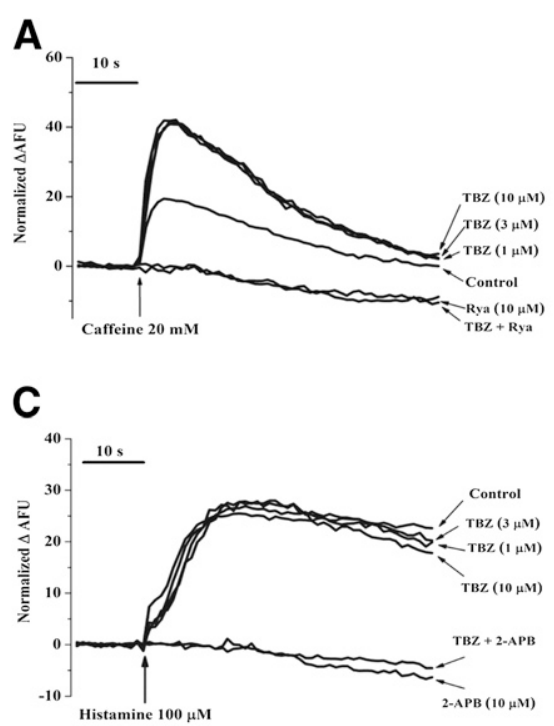

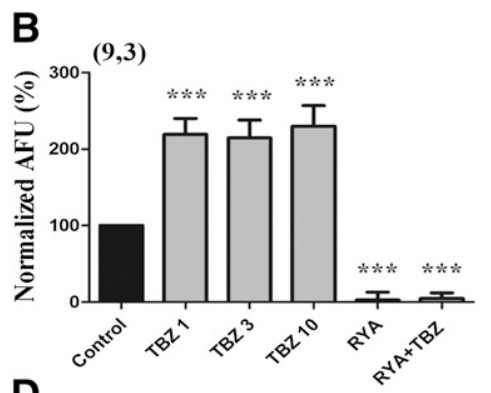

D

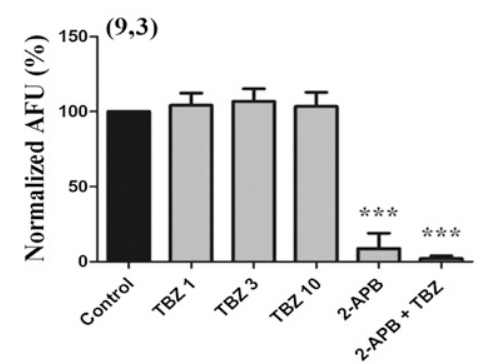

Fig. 7. Augmentation by TBZ of the $\left[\mathrm{Ca}^{2+}\right]_{\mathrm{c}}$ elevations triggered by caffeine, but not those of histamine, in rat embryo cortical neurons. Neurons were loaded with fluo-4, and experiments similar to those carried out with BCCs (Fig. 6) were performed. Neuron challenging with $20 \mathrm{mM}$ caffeine [arrow in (A)] or $100 \mu \mathrm{M}$ histamine [arrow in (C)] in the absence (control) or presence of TBZ (at 1-10 $\mu \mathrm{M}$ ), ryanodine (Rya; $10 \mu \mathrm{M}), 2-\mathrm{APB}(10 \mu \mathrm{M})$, combined Rya+TBZ, or 2-APB+TBZ. (A) Family of caffeine-elicited $\left[\mathrm{Ca}^{2+}\right]_{\mathrm{c}}$ traces monitored as normalized arbitrary fluorescence units (AFUs; ordinate); neuron treatments are labeled at the right part of each trace. (B) Pooled data of peak $\left[\mathrm{Ca}^{2+}\right]_{c}$ elevations; note the augmentation by TBZ (1, 3, and $\left.10 \mu \mathrm{M}\right)$ of the caffeine-elicited $\mathrm{Ca}^{2+}$ signal $(219.2 \% \pm 22.3 \%, 214.6 \% \pm 24.7 \%$, and $218.7 \% \pm 33 \%$, respectively) and the abolition of the responses by ryanodine, alone or combined with TBZ $(2.53 \% \pm 10.9 \%$ and $4.58 \% \pm 7.6 \%$, respectively; one-way ANOVA, $\mathrm{F}=37.09, P<0.0001$; Tukey post hoc comparison: *** $P<0.0001$, control vs. all pairs). (C) Family of histamine-elicited $\left[\mathrm{Ca}^{2+}\right]_{\mathrm{c}}$ traces monitored as normalized AFUs (ordinate). (D) Pooled data on the normalized $\left[\mathrm{Ca}^{2+}\right]_{\mathrm{c}}$ elevations by histamine showing that TBZ did not modify the histamine-elicited $\left[\mathrm{Ca}^{2+}\right]_{\mathrm{c}}$ transients; in the presence of 2 -APB and combined TBZ +2 -APB, the histamine response was abolished $(8.72 \% \pm 11 \%$ and $2.01 \% \pm 1.95 \%$, respectively; one-way ANOVA, $\mathrm{F}=93.20, P<0.0001 ;$ Tukey post hoc comparison: ${ }^{* * *} P<0.0001$ control vs. all pairs). Data in (B) and (D) are means \pm S.E.M. of the number of wells and cultures shown in parentheses on top of each column.

In support of such a hypothesis comes the clear-cut experiment showing that TBZ caused a notable and sustained facilitation of the caffeine secretory responses (Fig. 4). Of interest was the fact that this drug did not affect the histamine secretory responses that are known to be mediated by $\mathrm{IP}_{3} \mathrm{R}$ stimulation and $\mathrm{ER} \mathrm{Ca}^{2+}$ release (Stauderman and Pruss, 1990; Artalejo et al., 1993; Alonso et al., 1999) (Fig. 4). These two experiments strongly suggest that TBZ selectively enhances secretion through the CICR mechanism and helps to discard other targets such as cytoskeletal proteins, $\mathrm{Ca}^{2+}$-dependent intracellular vesicle transport, proteins of exocytosis, or other signaling pathways that facilitate vesicle priming and exocytosis, such as PKC activation by phorbol esters (Gillis et al., 1996; Yang et al., 2002) or cAMP-dependent PKA (Carabelli et al., 2003). In support of this explanation comes the observation that ER
$\mathrm{Ca}^{2+}$ depletion with SERCA blocker CPA drastically reduced all secretory responses to caffeine and histamine in both the absence and presence of TBZ (Fig. 5).

This hypothesis is strengthened by the more direct experimental approach to $\left[\mathrm{Ca}^{2+}\right]_{\mathrm{c}}$ change monitoring in BCCs challenged with caffeine or histamine. In the case of caffeine, the $\left[\mathrm{Ca}^{2+}\right]_{\mathrm{c}}$ elevations are entirely due to $\mathrm{ER} \mathrm{Ca}^{2+}$ release through RyRs of BCCs (Cheek et al., 1990, 1993; Alonso et al., 1999). Otherwise, histamine also releases ER $\mathrm{Ca}^{2+}$ into the cytosol of BCCs but through $\mathrm{IP}_{3} \mathrm{Rs}$ (Stauderman and Pruss, 1990; Artalejo et al., 1993; Alonso et al., 1999). We found that while TBZ caused a drastic augmentation of the caffeine-elicited $\left[\mathrm{Ca}^{2+}\right]_{\mathrm{c}}$ elevations (Fig. 6, A and $\mathrm{B}$ ), those generated by histamine were not modified by TBZ. This strongly supports the view that TBZ acts on the RyR to facilitate the CICR mechanism and to augment the
A

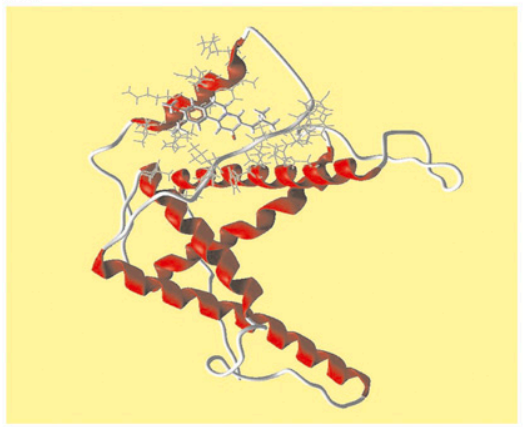

B

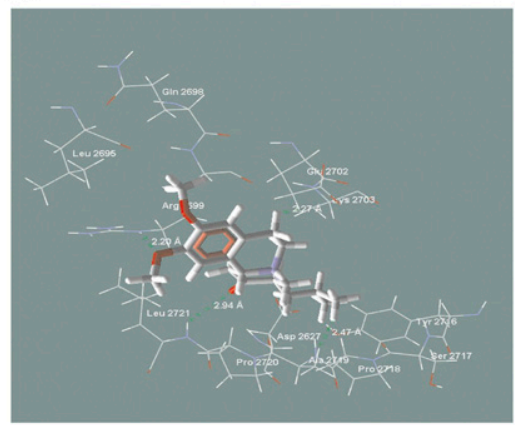

Fig. 8. Docking of tetrabenazine-ryanodine receptor complex. (A) Pose of TBZ (sticks, CPK-colored) in the type 3 RyR $\mathrm{Ca}^{2+}$-binding domain (main interacting residues in gray). (B) H-bonds (Arg 2599 and Leu 2721) and van der Waals contacts (Ala 2719 and Lys 2703) formed between amino acids (CPK-colored thin sticks) and TBZ (CPK-colored sticks). 


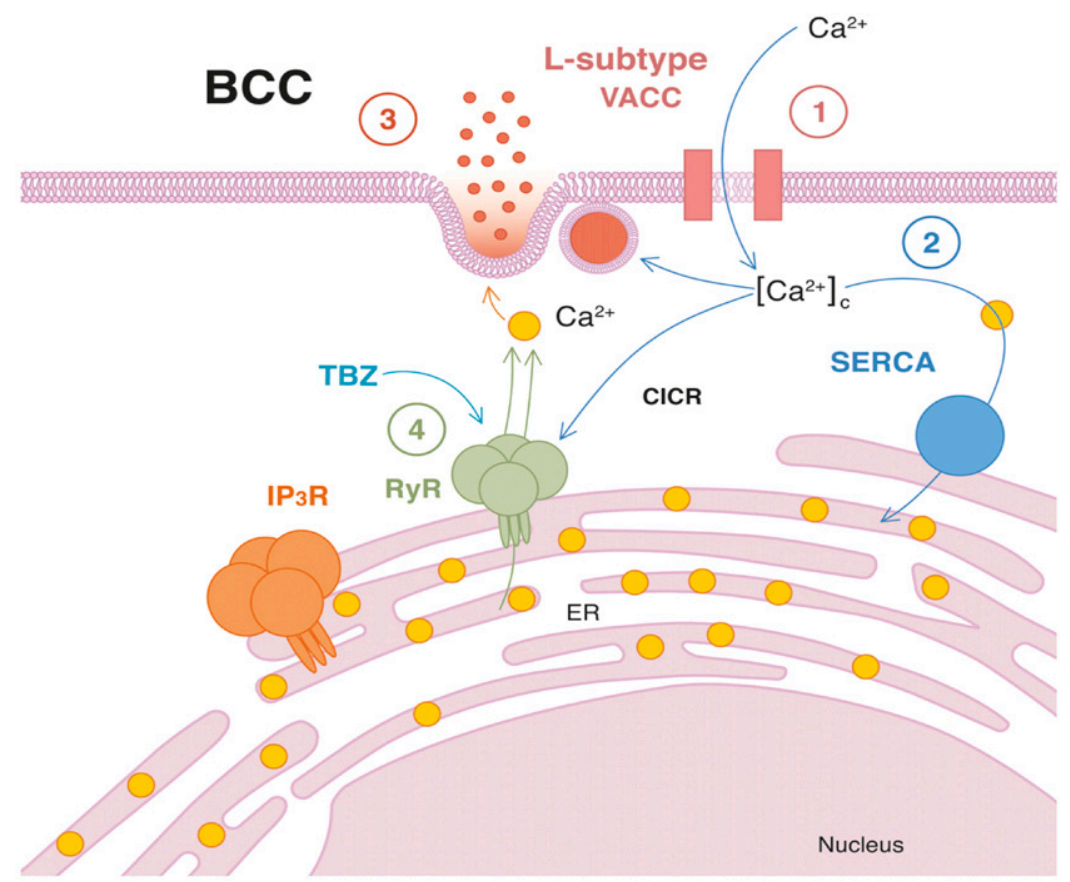

Fig. 9. Scheme showing the mechanism of action of TBZ involved in the augmentation of the exocytotic release of catecholamines triggered by $\mathrm{K}^{+}$-induced depolarization of the BCCs. (1) $\mathrm{K}^{+}$depolarization opens the L-subtype of VACC; (2) this leads to a sudden transient increase of the cytosolic $\mathrm{Ca}^{2+}$ concentration $\left(\left[\mathrm{Ca}^{2+}\right]_{\mathrm{c}}\right)$ that (3) triggers the rapid release of catecholamines from large dense-cored vesicles; (4) augmented $\left[\mathrm{Ca}^{2+}\right]_{\mathrm{c}}$ also triggers the CICR through the RyR to further augment the exocytotic catecholamine response (3).

caffeine-elicited (and the $\mathrm{K}^{+}$-elicited) exocytotic release of catecholamines (Figs. 1 and 2). The docking experiment of Fig. 8 strengthens this view.

By facilitating the release of $\mathrm{ER} \mathrm{Ca}^{2+}$ through the depolarization-triggered CICR mechanism of BCCs (Alonso et al., 1999), TBZ may just maintain a mild $\left[\mathrm{Ca}^{2+}\right]_{\mathrm{c}}$ elevation in between $\mathrm{K}^{+}$pulses, so that the $\mathrm{Ca}^{2+}$-dependent transport of new secretory vesicles from a reserve vesicle pool could be enhanced to refill the ready-release vesicle pool located at subplasmalemmal exocytotic active sites (Rettig and Neher, 2002). This mechanism was elegantly demonstrated first at the laboratory of Erwin Neher in single voltage-clamped BCCs using histamine to elicit a mild $\left[\mathrm{Ca}^{2+}\right]_{\mathrm{c}}$ elevation (von Rüden and Neher, 1993), using electrical pulses to elicit exocytosis. Later on, experiments on intact BCC populations challenged with physiologic acetylcholine or nicotine also showed a $\mathrm{Ca}^{2+}$-dependent vesicle transport facilitated by mild elevations of residual $\left[\mathrm{Ca}^{2+}\right]_{\mathrm{c}}$ or by $\mathrm{ER} \mathrm{Ca}^{2+}$ release (Arnaiz-Cot et al., 2008; de Diego et al., 2008). In this context, it seems that TBZ indirectly secures and maintains healthy secretory responses upon repeated depolarization of $\mathrm{K}^{+}$ stimuli by facilitating $\mathrm{ER} \mathrm{Ca}^{2+}$ release mediated by $\mathrm{RyR}$ activation, thus maintaining mild sustained $\left[\mathrm{Ca}^{2+}\right]_{\mathrm{c}}$ elevations to boost vesicle transport and the refilling, with new vesicles, of the secretory machinery at subplasmalemmal sites. This view is additionally reinforced by docking studies, which predict a direct interaction of TBZ with the phosphorylation domain of the RyR (Fig. 8). Thus, the RyR would be affecting the phosphorylation/dephosphorylation-dependent regulation of RyR exerted by both kinases and phosphatases.

In neurons, the $\mathrm{ER} \mathrm{Ca}^{2+}$ store may act as a $\mathrm{Ca}^{2+}$ sink (when partially empty) or as a $\mathrm{Ca}^{2+}$ source (when filled) (Tsien and Tsien, 1990); this is also true for BCCs (Lara et al., 1997; Milla et al., 2011). In this context, it seems that TBZ may regulate the $\mathrm{ER} \mathrm{Ca}^{2+}$ release during cell depolarization through the RyR, as shown by the experiments on $\left[\mathrm{Ca}^{2+}\right]_{\mathrm{c}}$ monitoring in Fig. 7. This facilitation of exocytosis is a novel mechanism of action of TBZ, independent of its well established mechanism of VMAT2 blockade and the depletion of central catecholamines, mainly of dopamine at the basal ganglia. Because the expression of VMAT2 is extremely scarce in BCCs (Weihe et al., 1994), it seems that the facilitation by TBZ of depolarization-elicited (and caffeine-elicited) catecholamine release in the cells is unrelated to VMAT blockade. A last comment on the potential clinical projection of basic findings reported here deserves attention.

In 2008, the US Food and Drug Administration approved TBZ for HD-associated chorea. Approval was based on clinical trials showing the drug was effective; however, side effects included increased risk of depression, suicidality, akathisia, anxiety, and Parkinsonism, among other tolerability issues (Huntington Study Group, 2006; Yero and Rey, 2008; Jankovic and Roos, 2014). In April 2017, the Food and Drug Administration approved a deuterated form of TBZ, deutetrabenazine, which also inhibits VMAT2. An indirect comparison on the tolerability of TBZ versus deutetrabenazine concluded that the latter had a more favorable profile of adverse events (Claassen et al., 2017). This may be due to a better pharmacokinetic profile and lesser dose of deutetrabenazine required to treat HD chorea (Dean and Sung, 2018). However, the greater toxicity of TBZ could also be associated with its new target described here-namely, the $\mathrm{ER}$ ryanodine receptor and enhanced $\mathrm{ER} \mathrm{Ca}^{2+}$ release into the cytosol. It is generally accepted that cell $\mathrm{Ca}^{2+}$ overload has neurotoxic effects that could lead to synaptic deficits and the adverse events of TBZ. Whether deutetrabenazine shares the ER $\mathrm{Ca}^{2+}$-mobilizing effect with its parent compound could be interesting to study.

Limitations of our study mainly deal with more direct approaches to better define the potential binding of TBZ to the ryanodine receptor. Also, experiments with ER-targeted aequorins, such as those we performed in a previous report (Alonso et al., 1999), will allow the direct monitoring of the changes undergone by the $\mathrm{ER} \mathrm{Ca}^{2+}$ store upon cell stimulation 
with high $\mathrm{K}^{+}$plus TBZ. Although these experiments may add value to our present work, we think that the present pharmacological study provides a quite solid collection of data to support the view that, beyond its well described inhibitory effect of VMAT2, TBZ also elicits the liberation of $\mathrm{ER} \mathrm{Ca}^{2+}$ into the cytosol through an entirely different action-namely, potentiation of the CICR mechanism of BCCs.

In conclusion, on the basis of the results here presented, the following conclusions can be established (Fig. 9): 1) TBZ potentiates exocytosis triggered by cell depolarization and caffeine, but not histamine; 2 ) such potentiating is not due to augmented $\mathrm{Ca}^{2+}$ entry; 3) rather, it depends on a functional, full $\mathrm{ER} \mathrm{Ca}^{2+}$ store, because it is due to the facilitation of ER $\mathrm{Ca}^{2+}$ release through the RyR; 4) this facilitation is not linked to VMAT2 blockade; and 5) enhanced $\mathrm{ER} \mathrm{Ca}^{2+}$ release also occurs in neurons. This could have clinical relevance in the context of TBZ use to treat HD chorea or other distonic disorders, from the point of view of either efficacy and/or side effects.

\section{Acknowledgments}

We thank Blanca Oriz Reyzabal for drawing the summary outline. We also thank the continued support of Fundación Teófilo Hernando (Madrid, Spain).

\section{Authorship Contributions}

Participated in research design: de Pascual, García.

Conducted experiments: de Pascual, Álvarez-Ortego, JacobMazariego.

Performed data analysis: de Pascual, Álvarez-Ortego, de los Ríos, Jacob-Mazariego.

Wrote or contributed to the writing of the manuscript: de Pascual, García.

\section{References}

Alonso MT, Barrero MJ, Michelena P, Carnicero E, Cuchillo I, García AG, GarcíaSancho J, Montero M, and Alvarez J (1999) $\mathrm{Ca}^{2+}$-induced $\mathrm{Ca}^{2+}$ release in chromaffin cells seen from inside the ER with targeted aequorin. J Cell Biol 144: 241-254.

Antkiewicz-Michaluk L, Wąsik A, Możdżeń E, Romańska I, and Michaluk J (2014) Antidepressant-like effect of tetrahydroisoquinoline amines in the animal model of depressive disorder induced by repeated administration of a low dose of reserpine: behavioral and neurochemical studies in the rat. Neurotox Res 26:85-98.

Arnáiz-Cot JJ, de Diego AM, Hernández-Guijo JM, Gandía L, and García AG (2008) A two-step model for acetylcholine control of exocytosis via nicotinic receptors. Biochem Biophys Res Commun 365:413-419.

Artalejo AR, García AG, and Neher E (1993) Small-conductance Ca(2+)-activated K+ channels in bovine chromaffin cells. Pflugers Arch 423:97-103.

Baker PF and Knight DE (1978) Calcium-dependent exocytosis in bovine adrenal medullary cells with leaky plasma membranes. Nature 276:620-622.

Benarroch EE (2013) Monoamine transporters: structure, regulation, and clinical implications. Neurology 81:761-768.

Blasco-Serra A Escrihuela-Vidal F, González-Soler EM, Martínez-Expósito F, Blasco-Ausina MC, Martínez-Bellver S, Cervera-Ferri A, Teruel-Martí V, and Valverde-Navarro AA (2015) Depressive-like symptoms in a reserpine-induced model of fibromyalgia in rats. Physiol Behav 151:456-462.

Borges R, Sala F, and García AG (1986) Continuous monitoring of catecholamine release from perfused cat adrenals. $J$ Neurosci Methods 16:289-300.

Carabelli V, Giancippoli A, Baldelli P, Carbone E, and Artalejo AR (2003) Distinct potentiation of L-type currents and secretion by cAMP in rat chromaffin cells. Biophys J 85:1326-1337.

Ceña V, Stutzin A, and Rojas E (1989) Effects of calcium and Bay K-8644 on calcium currents in adrenal medullary chromaffin cells. J Membr Biol 112:255-265.

Cheek TR, Moreton RB, Berridge MJ, Stauderman KA, Murawsky MM, and Bootman MD (1993) Quantal Ca2 + release from caffeine-sensitive stores in adrenal chromaffin cells. J Biol Chem 268:27076-27083.

Cheek TR, Murawsky MM, and Stauderman KA (1994) Histamine-induced Ca2+ entry precedes $\mathrm{Ca} 2+$ mobilization in bovine adrenal chromaffin cells. Biochem $J$ 304:469-476.

Cheek TR, O'Sullivan AJ, Moreton RB, Berridge MJ, and Burgoyne RD (1990) The caffeine-sensitive $\mathrm{Ca} 2+$ store in bovine adrenal chromaffin cells; an examination of its role in triggering secretion and $\mathrm{Ca} 2+$ homeostasis. FEBS Lett 266:91-95.

Claassen DO, Carroll B, De Boer LM, Wu E, Ayyagari R, Gandhi S, and Stamler D (2017) Indirect tolerability comparison of deutetrabenazine and tetrabenazine for Huntington disease. J Clin Mov Disord 4:3.

Cuchillo-Ibáñez I, Olivares R, Aldea M, Villarroya M, Arroyo G, Fuentealba J, García AG, and Albillos A (2002) Acetylcholine and potassium elicit different patterns of exocytosis in chromaffin cells when the intracellular calcium handling is disturbed. Pflugers Arch 444:133-142.

Dean M and Sung VW (2018) Review of deutetrabenazine: a novel treatment for chorea associated with Huntington's disease. Drug Des Devel Ther 12:313-319.

de Diego AM, Tapia L, Alvarez RM, Mosquera M, Cortés L, López I, Gutiérrez LM, Gandía L, and García AG (2008) A low nicotine concentration augments vesicle motion and exocytosis triggered by $\mathrm{K}(+)$ depolarisation of chromaffin cells. Eur J Pharmacol 598:81-86.

De Pascual R, Colmena I, Ruiz-Pascual L, Baraibar AM, Egea J, Gandía L, and García AG (2016) Regulation by L channels of $\mathrm{Ca}(2+)$-evoked secretory responses in ouabain-treated chromaffin cells. Pflugers Arch 468:1779-1792.

de Pascual R and García AG (2007) Ouabain augments and maintains the catecholamine release responses evoked by repetitive pulses of potassium, caffeine or histamine in perifused bovine chromaffin cells. Eur J Pharmacol 568:99-105.

Dixon WR, Garcia AG, and Kirpekar SM (1975) Release of catecholamines and dopamine beta-hydroxylase from the perfused adrenal gland of the cat. J Physiol 244: 805-824.

Douglas WW and Rubin RP (1963) The mechanism of catecholamine release from the adrenal medulla and the role of calcium in stimulus-secretion coupling. J Physiol 167:288-310.

Erickson JD, Eiden LE, Schafer MK, and Weihe E (1995) Reserpine- and tetrabenazine-sensitive transport of (3)H-histamine by the neuronal isoform of the vesicular monoamine transporter. J Mol Neurosci 6:277-287.

Fenwick EM, Marty A, and Neher E (1982) Sodium and calcium channels in bovine chromaffin cells. J Physiol 331:599-635.

Fleischer S, Ogunbunmi EM, Dixon MC, and Fleer EA (1985) Localization of Ca2+ release channels with ryanodine in junctional terminal cisternae of sarcoplasmic reticulum of fast skeletal muscle. Proc Natl Acad Sci USA 82:7256-7259.

García AG, García-De-Diego AM, Gandía L, Borges R, and García-Sancho J (2006) Calcium signaling and exocytosis in adrenal chromaffin cells. Physiol Rev 86: 1093-1131.

García AG, Sala F, Reig JA, Viniegra S, Frías J, Fontériz R, and Gandía L (1984) Dihydropyridine BAY-K-8644 activates chromaffin cell calcium channels. Nature 309:69-71.

Gillis KD, Mossner R, and Neher E (1996) Protein kinase C enhances exocytosis from chromaffin cells by increasing the size of the readily releasable pool of secretory granules. Neuron 16:1209-1220.

Goeger DE, Riley RT, Dorner JW, and Cole RJ (1988) Cyclopiazonic acid inhibition of the Ca2+-transport ATPase in rat skeletal muscle sarcoplasmic reticulum vesicles. Biochem Pharmacol 37:978-981.

Green DJ and Perlman RL (1981) On-line measurement of catecholamine secretion. Anal Biochem 110:270-276.

Hamill OP, Marty A, Neher E, Sakmann B, and Sigworth FJ (1981) Improved patchclamp techniques for high-resolution current recording from cells and cell-free membrane patches. Pflugers Arch 391:85-100.

Hendley ED and Welch BL (1975) Electroconvulsive shock: sustained decrease in norepinephrine uptake affinity in a reserpine model of depression. Life Sci 16: 45-54.

Henry JP, Botton D, Sagne C, Isambert MF, Desnos C, Blanchard V, Raisman-Vozari R, Krejci E, Massoulie J, and Gasnier B (1994) Biochemistry and molecular biology of the vesicular monoamine transporter from chromaffin granules. J Exp Biol 196: $251-262$

Hernández-Guijo JM, Maneu-Flores VE, Ruiz-Nuno A, Villarroya M, García AG, and Gandía L (2001) Calcium-dependent inhibition of $\mathrm{L}, \mathrm{N}$, and $\mathrm{P} / \mathrm{Q} \mathrm{Ca}^{2+}$ channels in chromaffin cells: role of mitochondria. J Neurosci 21:2553-2560.

Huntington Study Group (2006) Tetrabenazine as antichorea therapy in Huntington disease: a randomized controlled trial. Neurology 66:366-372.

Ikram H and Haleem DJ (2017) Repeated treatment with reserpine as a progressive animal model of depression. Pak J Pharm Sci 30:897-902.

Jankovic J (2016) Dopamine depleters in the treatment of hyperkinetic movement disorders. Expert Opin Pharmacother 17:2461-2470.

Jankovic J and Roos RA (2014) Chorea associated with Huntington's disease: to treat or not to treat? Mov Disord 29:1414-1418.

Lara B, López MG, Villarroya M, Gandía L, Cleeman L, Morad M, and García AG (1997) A caffeine-sensitive $\mathrm{Ca} 2+$ store modulates $\mathrm{K}+$-evoked secretion in chromaffin cells. Am J Physiol 272:C1211-C1221.

Lattanzio FA Jr, Schlatterer RG, Nicar M, Campbell KP, and Sutko JL (1987) The effects of ryanodine on passive calcium fluxes across sarcoplasmic reticulum membranes. J Biol Chem 262:2711-2718.

Mahapatra S, Calorio C, Vandael DH, Marcantoni A, Carabelli V, and Carbone E (2012) Calcium channel types contributing to chromaffin cell excitability, exocytosis and endocytosis. Cell Calcium 51:321-330.

Mandela P, Chandley M, Xu YY, Zhu MY, and Ordway GA (2010) Reserpine-induced reduction in norepinephrine transporter function requires catecholamine storage vesicles. Neurochem Int 56:760-767.

Mark Wightman R, Domínguez N, and Borges R (2018) How intravesicular composition affects exocytosis. Pflugers Arch 470:135-141.

Maruyama T, Kanaji T, Nakade S, Kanno T, and Mikoshiba K (1997) 2APB, 2 aminoethoxydiphenyl borate, a membrane-penetrable modulator of Ins $(1,4,5) \mathrm{P} 3$ induced $\mathrm{Ca} 2+$ release. $J$ Biochem 122:498-505.

Milla J, Montesinos MS, Machado JD, Borges R, Alonso E, Moreno-Ortega AJ, CanoAbad MF, García AG, and Ruiz-Nuño A (2011) Ouabain enhances exocytosis through the regulation of calcium handling by the endoplasmic reticulum of chromaffin cells. Cell Calcium 50:332-342.

Moro MA, López MG, Gandía L, Michelena P, and García AG (1990) Separation and culture of living adrenaline- and noradrenaline-containing cells from bovine adrenal medullae. Anal Biochem 185:243-248.

Mundorf ML, Troyer KP, Hochstetler SE, Near JA, and Wightman RM (2000) Vesicular $\mathrm{Ca}(2+)$ participates in the catalysis of exocytosis. J Biol Chem 275: 9136-9142. 
Neher E (1998) Vesicle pools and Ca2+ microdomains: new tools for understanding their roles in neurotransmitter release. Neuron 20:389-399.

Nowicky AV and Duchen MR (1998) Changes in [Ca2+]i and membrane currents during impaired mitochondrial metabolism in dissociated rat hippocampal neurons. J Physiol 507:131-145.

Pan CY and Fox AP (2000) Rundown of secretion after depletion of intracellular calcium stores in bovine adrenal chromaffin cells. J Neurochem 75:1132-1139.

Pessah IN, Francini AO, Scales DJ, Waterhouse AL, and Casida JE (1986) Calciumryanodine receptor complex. Solubilization and partial characterization from skeletal muscle junctional sarcoplasmic reticulum vesicles. J Biol Chem 261:8643-8648.

Rettig $\mathrm{J}$ and Neher E (2002) Emerging roles of presynaptic proteins in $\mathrm{Ca}^{++}$-triggered exocytosis. Science 298:781-785.

Seidler NW, Jona I, Vegh M, and Martonosi A (1989) Cyclopiazonic acid is a specific inhibitor of the Ca2+-ATPase of sarcoplasmic reticulum. J Biol Chem 264 17816-17823.

Stauderman KA and Pruss RM (1990) Different patterns of agonist-stimulated increases of ${ }^{3} \mathrm{H}$-inositol phosphate isomers and cytosolic $\mathrm{Ca}^{2+}$ in bovine adrenal chromaffin cells: comparison of the effects of histamine and angiotensin II. $J$ Neurochem 54:946-953.

Tsien RW and Tsien RY (1990) Calcium channels, stores, and oscillations. Annu Rev Cell Biol 6:715-760.

Villalobos C, Nuñez L, Montero M, García AG, Alonso MT, Chamero P, Álvarez J, and García-Sancho J (2002) Redistribution of $\mathrm{Ca}^{2+}$ among cytosol and organella during stimulation of bovine chromaffin cells. FASEB $J$ 16:343-353.
Villarroya M, Olivares R, Ruíz A, Cano-Abad MF, de Pascual R, Lomax RB, López MG, Mayorgas I, Gandía L, and García AG (1999) Voltage inactivation of $\mathrm{Ca}^{2+}$ entry and secretion associated with $\mathrm{N}$ - and $\mathrm{P} / \mathrm{Q}$-type but not L-type $\mathrm{Ca}^{2+}$ channels of bovine chromaffin cells. $J$ Physiol 516:421-432.

von Rüden L and Neher E (1993) A Ca-dependent early step in the release of cat echolamines from adrenal chromaffin cells. Science 262:1061-1065.

Weihe E, Schäfer MK, Erickson JD, and Eiden LE (1994) Localization of vesicular monoamine transporter isoforms (VMAT1 and VMAT2) to endocrine cells and neurons in rat. J Mol Neurosci 5:149-164.

Yang Y, Udayasankar S, Dunning J, Chen P, and Gillis KD (2002) A highly Ca2+sensitive pool of vesicles is regulated by protein kinase $\mathrm{C}$ in adrenal chromaffin cells. Proc Natl Acad Sci USA 99:17060-17065.

Yero T and Rey JA (2008) Tetrabenazine (xenazine), an FDA-approved treatment option for Huntington's disease-related chorea. $P \& T$ 33:690-694.

Yuchi Z, Lau K, and Van Petegem F (2012) Disease mutations in the ryanodine receptor central region: crystal structures of a phosphorylation hot spot domain. Structure 20:1201-1211.

Address correspondence to: Antonio G. García, Instituto Teófilo Hernando, Departamento de Farmacología y Terapéutica, Facultad de Medicina, Universidad Autónoma de Madrid, Arzobispo Morcillo, 4. 28029 Madrid, Spain. E-mail: agg@uam.es 